\title{
Retrospective analysis of uncertain eruption precursors at La Soufrière volcano, Guadeloupe, 1975-77: volcanic hazard assessment using a Bayesian Belief Network approach
}

Thea K Hincks ${ }^{*}$, Jean-Christophe Komorowski ${ }^{2}$, Stephen R Sparks ${ }^{1}$ and Willy P Aspinall ${ }^{1,3}$

\begin{abstract}
Background: Scientists monitoring active volcanoes are increasingly required to provide decision support to civil authorities during periods of unrest. As the extent and resolution of monitoring improves, the process of jointly interpreting multiple strands of indirect evidence becomes increasingly complex. Similarities with uncertainties in medical diagnosis suggest a formal evidence-based approach, whereby monitoring data are analysed synoptically to provide probabilistic hazard forecasts. A statistical tool to formalize such inferences is the Bayesian Belief Network (BBN). By explicitly representing conditional dependencies between the volcanological model and observations, BBNs use probability theory to treat uncertainties in a rational and auditable manner, as warranted by the strength of the scientific evidence. A retrospective analysis is given for the 1976 Guadeloupe crisis, using a BBN to provide inferential assessment of the state of the evolving magmatic system and probability of incipient eruption. Conditional dependencies are characterized quantitatively by structured expert elicitation.
\end{abstract}

Results: Analysis of the available monitoring data suggests that at the height of the crisis the probability of magmatic intrusion was high, in accordance with scientific thinking at the time. The corresponding probability of magmatic eruption was elevated in July and August 1976 and signs of precursory activity were justifiably cause for concern. However, collective uncertainty about the future course of the crisis was also substantial. Of all the possible scenarios, the most likely outcome evinced by interpretation of observations on 31 August 1976 was 'no eruption' (mean probability 0.5 ); the chance of a magmatic eruption/blast had an estimated mean probability of $\sim 0.4$. There was therefore no evidential basis for asserting one scenario to be significantly more likely than another.

Conclusions: Our analysis adds objective probabilistic expression to the volcanological narrative at the time of the 1976 crisis, and demonstrates that a formal evidential case could have supported the authorities' concerns about public safety and decision to evacuate. Revisiting the episode highlights many challenges for modern, contemporary decision making under conditions of considerable uncertainty, and suggests the BBN is a suitable framework for marshalling multiple, uncertain observations, model results and interpretations. The formulation presented here can be developed as a tool for ongoing use in the volcano observatory.

Keywords: Volcanic hazards; Multi-parameter monitoring; Bayesian inference; Uncertainty; Decision making; Expert judgement

\footnotetext{
* Correspondence: t.hincks@bristol.ac.uk

${ }^{1}$ School of Earth Sciences, University of Bristol, Queen's Road, Bristol BS8 1RJ, UK

Full list of author information is available at the end of the article
} 


\section{Background}

During a volcanic crisis, decisions typically have to be made with limited information and high uncertainty, on short time scales. The primary goal is to minimise loss and damage from any event, but social and economic loss resulting from false alarms and evacuations must also be considered (Woo 2008). Although it is not the responsibility of the scientist to call an evacuation or manage a crisis, there is an increasing requirement to assess risks and present scientific information and associated uncertainties in ways that enable public officials to make urgent evacuation decisions or other mitigation policy choices.

In the interests of safety for both exposed populations and scientists in the field, Aspinall et al. (2003) stress the need for a robust and defensible evidence-based approach to hazard and risk assessment. Although applied in medicine (Sackett et al. 1996), formal evidence-based decision-making is not common practice in volcanology (or indeed other areas of natural hazard and risk assessment). This paper aims to demonstrate the practicality and utility of this approach, particularly in situations with uncertain scientific information, limitations of understanding, and intrinsically unpredictable outcomes. The process of identifying and attempting to quantify sources of uncertainty (both epistemic and aleatory) can be very informative, from all key perspectives (scientists, risk assessors and stakeholders).

Scientific disagreements and political contretemps surrounded the 1976 volcanic crisis of La Soufrière volcano, Guadeloupe (Fiske, 1984; Feuillard et al. 1983) ${ }^{\mathrm{a}}$. These controversies and subsequent costly evacuation highlighted the need for a more structured and transparent approach to the use of scientific advice in volcanic hazard assessment (Aspinall and Woo 1994). A key question that needed to be answered in 1976 was: "Is the current state of unrest magmatic in origin, and if so, what is the probability of an explosive volcanic eruption?". An additional question was: "If an explosive eruption occurs, what is the probability that it occurs at the onset or very near the onset of the eruptive activity?" Indeed, the predominant working hypothesis - which influenced the scientific attitude of many and drove the political management of the crisis - was that if there were to be paroxysmal explosive activity then it was more likely to occur at the onset of an eruption, as in the tragic 1902 eruption of La Montagne Pelée, Martinique, rather than later.

These questions will be just as pressing if, in the near future, the signs of volcanic unrest manifested since 1992 in Guadeloupe (Komorowski et al. 2005; Villemant et al. 2005) were to escalate. The public clashes in 1976 left a legacy of loss of trust in scientists and authorities there. Any future crisis will need to be managed with care and a transparent and robust approach to information sharing if trust is to be fully restored. Villemant et al. (2005) remark that it remains very difficult to interpret monitoring data in terms of deep volcanic processes, for example to identify or differentiate between magmatic activity and purely hydrothermal activity. At the time of the 1976 crisis, knowledge of the style and magnitude of past eruptive activity of La Soufrière was limited, and multi-parameter monitoring data (e.g. seismicity, deformation, fluid geochemistry) inconclusive and, even jointly, insufficient to reliably inform hazard mitigation decisions.

Following the approach of Aspinall et al. (2003), we use a Bayesian Belief Network (BBN) to interpret jointly the observational evidence available in 1976, and make inferences about the key volcanic states and processes at the time. The output is a retrospective probabilistic forecast that communicates the perceived level of hazard and associated scientific uncertainty. BBNs have been widely applied in engineering and medical decision support systems (Spiegelhalter et al. 1993). The Bayesian methodology is also becoming increasingly used for decision support in natural hazard assessments, including flood risk, terrain analysis and water quality (see, e.g. Molina et al. 2005; Stassopoulou et al. 1998; Borsuk et al. 2003, respectively); and operational risk (Cowell et al. 2007; Neil et al. 2005).

The graphical nature of the BBN makes it an efficient and intuitive means for describing a complex, multifaceted system. Causal relationships are easily visualised, and can be presented in a compact and easily communicated format (see Methods). Measures such as mutual information (the strength of the relationship between a pair of nodes - see Methods) and entropy can also be used to assess the relative evidential value of individual observations and identify where further data or research may improve the hazard forecast or help reduce uncertainty. All these features should aid communication between volcanologists, risk assessors and stakeholders critical to the successful management of any volcanological unrest situation. Complementary approaches include logic or event trees (e.g. Newhall and Hoblitt 2002; Marzocchi et al. 2004; Marzocchi et al. 2008; Sobradelo and Martí 2010) - these are generally designed to capture a sequence of events and observations rather than describe the primary components and process interactions of the system; however, the basic probability calculus is largely the same.

\section{Volcanic record of La Soufrière, Guadeloupe}

La Soufrière is the most recently active part of the composite, andesitic La Grande Découverte-Soufrière volcanic (GDSV) complex, located in southern Basse-Terre, Guadeloupe (Figures 1 and 2). Comprehensive descriptions of the geological setting and volcanic activity (Komorowski et al. 2005; Boudon et al. 2008; Samper 

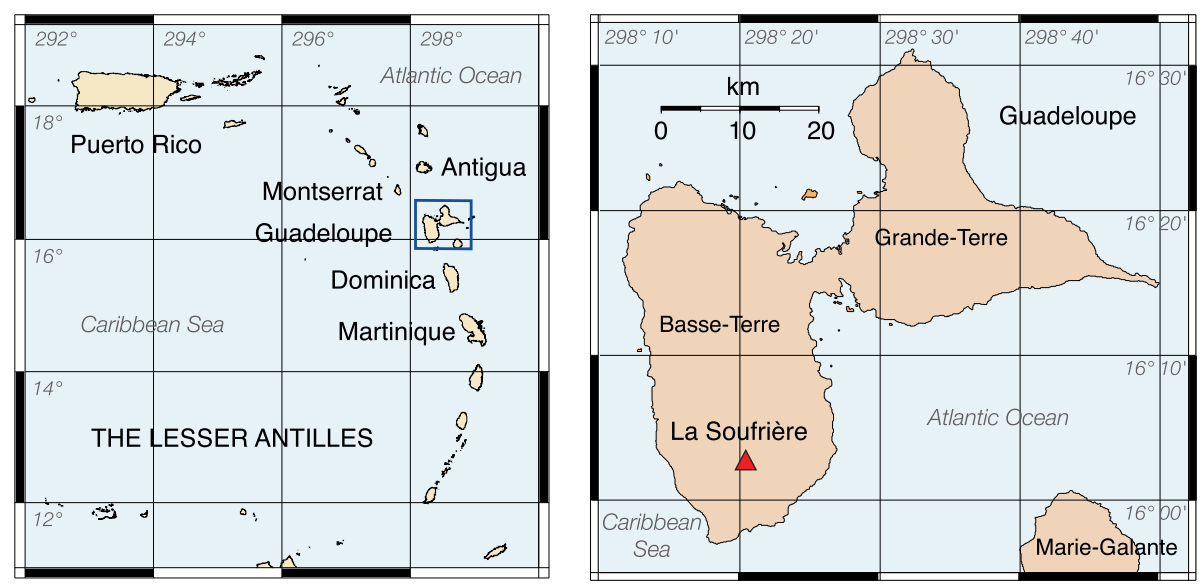

Figure 1 Map of Guadeloupe. Location of La Soufrière volcano, Guadeloupe, in the Lesser Antilles island arc, eastern Caribbean.

et al. 2009; Legendre et al. 2010; Legendre 2012) are summarised briefly here. Past activity has ranged from effusive fissure eruptions, explosive magmatic and phreatic episodes, and major sector collapse events (Boudon et al. 1987; Carlut et al. 2000; Komorowski et al. 2008a; Samper et al. 2007) (Table 1).

The GDSV complex consists of three major composite andesitic volcanoes formed over the last $445 \mathrm{ky}$ : the Grande-Découverte volcano, the Carmichaël volcano, and the most recent La Soufrière volcano (Boudon et al. 1988; Komorowski et al. 2005; Samper et al. 2009). Although the Grande-Découverte phase ( 445 to $42 \mathrm{ka}$ ) was dominated by effusive activity it was interrupted by at least three major caldera-forming explosive eruptions approximately at 140,108 , and $42, \mathrm{ka}$. The 42 , ka caldera eruption marks the end of the Grande-Découverte phase (Boudon et al. 1988; Komorowski et al. 2005). This was followed by effusive and explosive activity, forming a new edifice in the caldera. The Carmichaël phase (35 to $11.5 \mathrm{ka}$ ) was dominated by effusive to explosive domegrowth and ended with a sector collapse and associated laterally-directed explosions without a magmatic component. The Soufrière phase (last $9 \mathrm{ky}$ ) has been characterized by recurrent effusive to explosive dome-growth and up to eight sector collapse events (Komorowski et al. 2005; Boudon et al. 2007; Komorowski et al. 2008b) with major events about 8 and $3 \mathrm{ka}$ (Boudon et al. 2007). Several of the sector-collapses were associated with lateral blasts (2-5 events) and a magmatic component (Boudon et al. 1987; Komorowski et al. 2008b).

At least three low to moderate (VEI 2-3) explosive eruptions occurred in the last 9000 years, and three or more much larger VEI 4-5 explosive eruptions in the period from 11.5 to $42.5 \mathrm{ka}$. The last significant explosive magmatic eruption (VEI 2-3, $1530 \mathrm{AD}$ ) produced a multi-stage sequence: a debris avalanche from sector collapse; pumice and scoria fallout from a short-lived subplinian convective column; column collapse scoria pyroclastic density currents, and an andesite lava dome that ended the eruption (Boudon et al. 2008; Komorowski et al. 2008a). The petrology and isotopic signature of the $1530 \mathrm{AD}$ erupted products suggest a zoned magma chamber at a depth of about $6 \mathrm{~km}$ periodically fed by basaltic magma from depth (Touboul et al. 2007; Boudon et al. 2008).

Carbon-14 dating of lahar, pyroclastic surge and pumice fall deposits indicate that further activity occurred between $1530 \mathrm{AD}$ and the arrival of European settlers in $1635 \mathrm{AD}$ (Boudon et al. 2008; Legendre 2012). Historical activity has been phreatic, characterized by explosions, episodes of vigorous degassing and ash venting. Major phreatic eruptions occurred in 1797-98 and 1976-77, with minor events in 1690, 1812, 1836-1837 and 1956 (Boudon et al. 1988; Komorowski et al. 2005). Hazards associated with phreatic activity include vertical and laterally-directed blasts, ash fall, small-volume non-magmatic pyroclastic density currents, debris flows, acid degassing, potential contamination of the groundwater and aquifer. Major phreatic eruptions could trigger flank collapse and lateral non-magmatic blasts.

\section{The 1975-77 episode of eruptive unrest at La Soufrière}

Between 1956 and June 1975 the mean monthly number of recorded volcano-tectonic (VT) earthquakes was 15 and the mean monthly number of felt VT earthquakes was about 0.2 (Dorel and Feuillard 1980; IPGP 1956-2013). This 19-year average is considered the baseline level of VT activity. In contrast to previous phreatic eruptions of La Soufrière (including the last short-lived phreatic eruption of 19-27 October 1956: Jolivet, 1958), a one year period of steadily increasing volcanic seismicity was recorded and felt in Guadeloupe prior to the start of surface activity. This pre-eruptive seismicity was characterized by large numbers of recorded and felt events, and the occurrence of three distinct successive earthquake swarms of increasing 


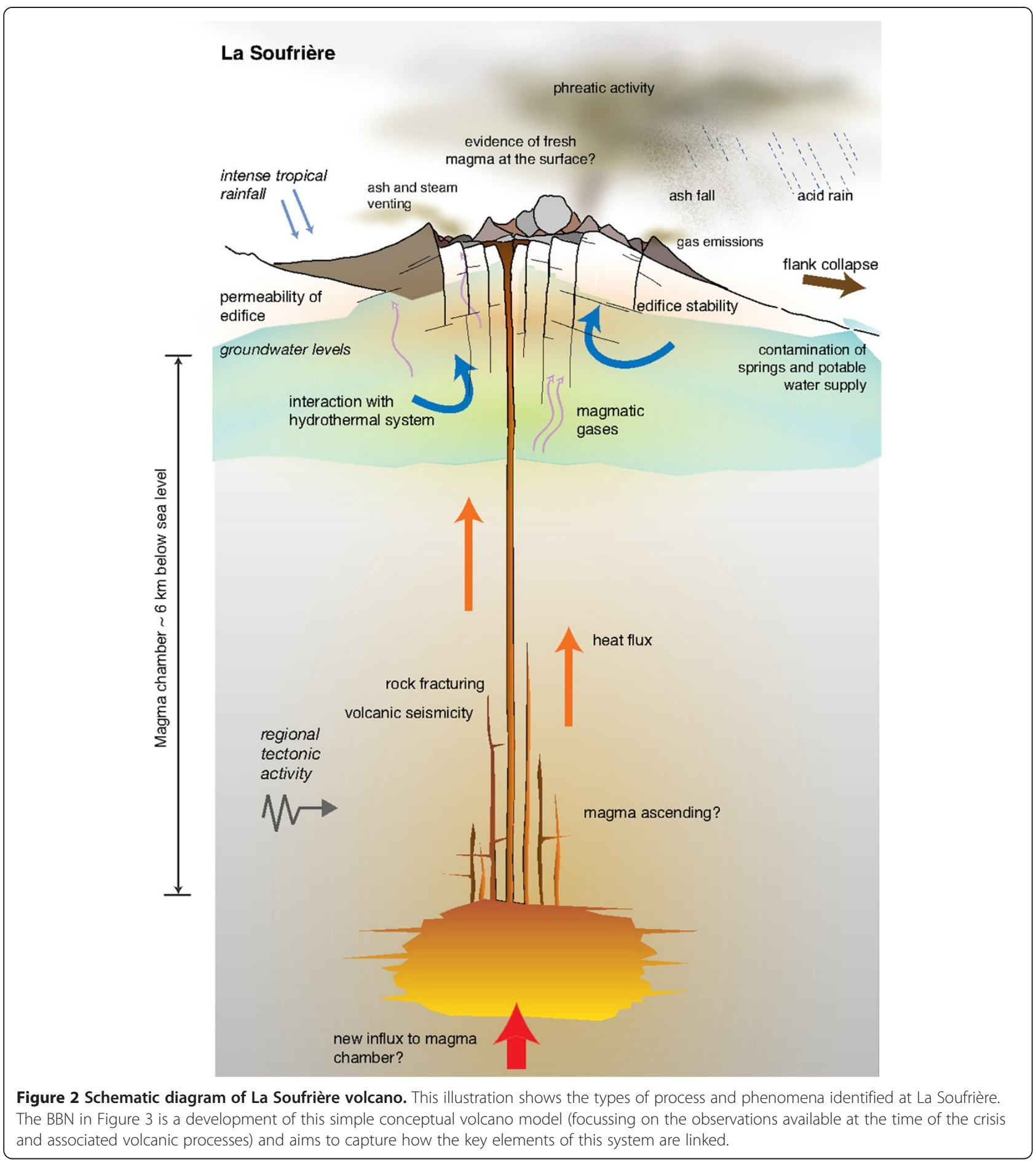

released seismic energy. An initial swarm of $30 \mathrm{VTs}$, one of which was felt, occurred in July 1975. Monthly seismicity continued to increase in the following months and was characterized by two significant swarms of VTs in November to December 1975 (total of 296 VTs and 4 felt events) and in March to June 1976 (total of 2713 VTs and 59 felt events). Although by this stage the rapidly escalating seismicity was about 45 times greater than the baseline monthly rate there were no discernible changes in fumarolic activity (Dorel and Feuillard 1980; Feuillard et al. 1983). However, on 9 June 1976 a minor landslide occurred on the La Ty fault and new fractures were observed on the road at the base of the dome (Feuillard 2011). An explosion occurred at 08:55 local time on 8 July 1976, marking the onset of nine months of complex eruptive activity. The explosion reactivated the 1956 phreatic eruptive fracture and 
Table 1 Eruptive chronology of La Soufrière in the last 9000 years, with calibrated radiocarbon dates (CE: common era and BCE: before common era) from Boudon et al. (1988); Komorowski et al. (2005; 2008); Boudon et al. (2007 and 2008); Siebert and Simkin (2002-2011)

\begin{tabular}{|c|c|c|}
\hline Start date & Type & Description \\
\hline 6535 BCE & $\mathrm{E}$ & Edifice collapse - not magmatic, not explosive \\
\hline 4000 BCE ? & M & VEI 2 explosive Strombolian \\
\hline 3600 BCE ? & M & VEI 2 explosive Vulcanian \\
\hline $3360 \mathrm{BCE}$ & M & VEI 3 magmatic dome eruption, possibly explosive \\
\hline 2400 BCE ? & $\mathrm{E}$ & Edifice collapse - not magmatic, not explosive \\
\hline 1625 BCE & M & VEI 3-4 explosive magmatic with edifice collapse and blast (possible cryptodome?) \\
\hline 1400 BCE & M & VEI 3-4 explosive magmatic with edifice collapse and blast (cryptodome) \\
\hline 1065 BCE ? & $\mathrm{E}$ & Edifice collapse - not magmatic, not explosive \\
\hline 980 BCE & M & VEI 3 magmatic dome eruption, possibly explosive \\
\hline $465 \mathrm{BCE}$ & M & VEI 3 explosive magmatic dome eruption with edifice collapse and blast \\
\hline 310 CE & M & VEI 2 explosive Strombolian \\
\hline 605 CE & $\mathrm{E}$ & Edifice collapse - not magmatic, not explosive \\
\hline $1530 \mathrm{CE}$ & M & VEI 2-3 explosive Subplinian and dome magmatic eruption with edifice collapse \\
\hline 1635 CE ? & M & VEI 2 explosive magmatic, possibly Vulcanian \\
\hline $1690 \mathrm{CE}$ & $P$ & VEI 1 Phreatic - not magmatic but explosive (Komorowski et al. 2005) \\
\hline 1797 CE & $P$ & VEI 1 Phreatic - not magmatic but explosive (Komorowski et al. 2005) \\
\hline 1812 CE & $P$ & VEI 1 Phreatic - not magmatic but explosive (Komorowski et al. 2005) \\
\hline 1836 CE & $P$ & VEI 1 Phreatic - not magmatic but explosive (Komorowski et al. 2005) \\
\hline 1956 CE & $P$ & VEl 1 Phreatic - not magmatic but explosive (Komorowski et al. 2005) \\
\hline 1976 CE & $\mathrm{F}$ & VEI 1 failed (still-born) magmatic explosive (Komorowski et al. 2005) \\
\hline
\end{tabular}

Events are classified as non-magmatic, non explosive edifice collapses (E); magmatic explosive (M); non magmatic but explosive phreatic events (P), or failed magmatic $(F)$, as in 1976. A question mark indicates the eruption date is uncertain. The last confirmed major magmatic eruption of La Soufrière was 1530 AD (Boudon et al. 2008 and Komorowski et al. 2008a, 2008b). Phreatic eruptions (identified from historic reports as well as stratigraphic evidence) appear to be more frequent in the last 400 years, however there is significant bias in the catalogue. Evidence of less energetic eruptions before settlement on the island is likely to have been missed, destroyed during larger magmatic events, or poorly preserved in the stratigraphic record. This is also the case for low magnitude magmatic eruptions (VEI 2) as shown by Legendre (2012).

produced $60 \%$ by volume $\left(0.6 \times 10^{6} \mathrm{~m}^{3}\right)$ of the total ejected solids from the entire 1976-1977 crisis (Le Guern et al. 1980). Table 2 summarises the timeline of key eruptive phenomena, monitoring and phenomenological data (observables) and associated decisions by the scientific team and the public officials.

The 1975-1977 unrest and eruptive crisis lasted 22.5 months from 24 July 1975 until 15 June 1977, during which 16493 VTs were recorded of which 153 were felt (Dorel and Feuillard 1980; Feuillard et al. 1983; IPGP, 1956-2013; Feuillard 2011). A total of 26 explosions occurred in two phases over the 9 months from 8 July 1976-1 March 1977. The eruption can be divided into five main phases: a) a pre-eruptive unrest phase from 24 July 1975-7 July 1976 with steadily increasing and escalating seismicity (3189 VTs, 64 felt VTs); b) eruptive phase 1 from 8 July to 10 November 1976, the most intense in terms of explosive activity (17 explosions) and seismicity (11,649 VTs, 68 felt VTs); c) eruptive phase 2 from 11 November 1976 to 4 January 1977 (the least intense) with no explosions, frequent ash venting episodes, and a decrease in recorded seismicity (968 VTs; 9 felt VTs); d) eruptive phase 3 from 5 January to 1 March 1977, which showed a renewal of explosive activity ( 9 explosions, some amongst the largest of the entire crisis) and a decline in seismicity (475 VTs, 7 felt VTs); e) a post-eruptive unrest phase beginning 2 March during which seismicity returned to almost background levels by 15 June 1977, formally marking the end of the eruption. Excluding volcanic tremor, recorded seismicity was poorly correlated with eruptive phenomena.

The 1975-77 eruption produced an estimated $10^{6} \mathrm{~m}^{3}$ of non-juvenile tephra deposited as very fine, thin ash up to $10-15 \mathrm{~km}$ west and south of the summit (Heiken et al. 1980; Le Guern et al. 1980). Ballistic blocks (a few kilogrammes to several tonnes) were ejected up to 1.6 $\mathrm{km}$ from the vent. The eruption was accompanied by morphological changes including opening of two new major sets of fractures (several hundred meters long, several decameters wide) in the dome, and the widening and deepening of historically old craters and fractures. Small-volume pyroclastic density currents from the 
Table 2 Timeline of the volcanic crisis from July 1975 - June 1977

\begin{tabular}{|c|c|c|c|c|}
\hline Date & $\begin{array}{l}\text { Eruptive } \\
\text { outcome }\end{array}$ & Key analytical \& recorded observables & Key scientific decisions & Key official decisions \\
\hline \multicolumn{5}{|c|}{24 July 1975 - 7 July 1976: non-eruptive unrest phase: escalating seismicity (3189 recorded VTs, 64 felt VTs) } \\
\hline 31 Jul 75 & & $\begin{array}{l}\text { Seismic swarm } 124-26 / 07 \text { ( } 30 \mathrm{VT}, 1 \text { felt; } 3 \\
\text { stations) } 2 \times 19 \text { year baseline of } 15 \mathrm{VT} / \mathrm{month} \\
0.2 \mathrm{felt} / \mathrm{month}\end{array}$ & Scientific vigilance - authorities informed & \\
\hline Nov-Dec 75 & & $\begin{array}{l}\text { Seismic swarm 2: 13/11 to 30/12 (296 VTs, } 4 \text { felt) } \\
\text { 20x baseline }\end{array}$ & $\begin{array}{l}\text { 13/11: MF warns Préfet unrest could lead to } \\
\text { eruption }\end{array}$ & $\begin{array}{l}\text { 13/11: Préfet requests Volcano Contingency Plan } \\
\text { (VCP) }\end{array}$ \\
\hline 10 Jan 76 & & $\begin{array}{l}\text { Decline in seismic activity to } 2.6 x \text { baseline followed } \\
\text { by increase }\end{array}$ & $\begin{array}{l}\text { 19/01: MF } 2^{\text {nd }} \text { note to Préfet informing on } \\
\text { increasing seismicity (number of VTs and } \\
\text { energy) }\end{array}$ & $\begin{array}{l}\text { 10/01: First draft of VCP produced; 4/02: VCP to } \\
\text { local authorities for confidential review }\end{array}$ \\
\hline 24-25 Mar 76 & & $\begin{array}{l}\text { Onset seismic swarm 3: } 220 \mathrm{VTs}, 12 \text { felt VTs in } 24 \mathrm{hr} \text {. } \\
\text { Total for swarm } 3 \text { from 1/03 to 07/07/76: } 2713 \mathrm{VTs} \text {, } \\
59 \text { felt, } 45 \times \text { baseline }\end{array}$ & & $\begin{array}{l}\text { 25/03: French government alerted; } 1^{\text {st }} \text { local press } \\
\text { article on unrest - spontaneous evacuation of } 200 \\
\text { persons }\end{array}$ \\
\hline 29-30 Mar 76 & & $\begin{array}{l}\text { March: marked increase in seismicity, } 607 \mathrm{VTs}, 22 \text { felt, } \\
41 \times \text { baseline }\end{array}$ & $\begin{array}{l}\text { 30/03: HT: } 48 \text { h visit with GA \& GJ: HT gives } \\
\text { reassuring assessment, uncertain unrest will lead } \\
\text { to eruption, but given an eruption low probability } \\
\text { that it will be "cataclysmic" }\end{array}$ & $\begin{array}{l}\text { 29/03: Préfet holds crisis response meeting; VCP } \\
\text { officially issued defining risk area \& evacuation } \\
\text { centres; Préfet requests risk map from BRGM }\end{array}$ \\
\hline 1-12 Apr 76 & & & & 1-12/04: Préfet reviews VCP with town officials \\
\hline \multirow[t]{2}{*}{ 22-23 Apr 76} & & $120 \mathrm{VTs}, 7$ felt in $48 \mathrm{hr}$ & \multirow{2}{*}{$\begin{array}{l}\text { 20/04: meeting gov Paris, enhance observatory } \\
\text { capacity, HT: unrest not exceptional cannot } \\
\text { exclude serious outcome, important precautionary } \\
\text { measures needed; } 23 / 04 \text { : MF reassuring, situation } \\
\text { serious but not critical, nothing likely } \leq 4 \text { months } \\
\text { given current seismicity trend; 30/04: MF eruption } \\
\text { probable July-August if unrest continues }\end{array}$} & \multirow{2}{*}{$\begin{array}{l}\text { 23/04: Préfet press conference, VCP made public; } \\
\text { 30/04: Overseas Minister visits Observatory with } \\
\text { National Civil Protection to validate VCP, national } \\
\text { VCP on file at Paris Civil Protection Office; 22/05: } \\
\text { President of France visits, requests zero risk policy }\end{array}$} \\
\hline & & $\begin{array}{l}\text { April: seismicity still increasing, } 747 \text { VTs, } 14 \text { felt, 50x } \\
\text { baseline }\end{array}$ & & \\
\hline
\end{tabular}

$100 \mathrm{VTs}, 4$ felt in $48 \mathrm{hr}$;

May: $611 \mathrm{VTs}, 9$ felt, $41 \times$ baseline

4-9 Jun 76

4/06: $169 \mathrm{VTs} ; 8-9 / 06: 65 \mathrm{VTs} 10$ felt in $24 \mathrm{~h}$; 9/06 landslide on La Ty fault SE dome fissures on road base dome aligned La Ty fault

02 Jul 76

June: 668 VTs, 14 felt, 45x baseline

02/06: new BRGM risk map sent to Préfet; 14/06: MF note to Préfet, risk map exaggerates risk of PDCs, revision to include ashfall \& mudflow risk

MF $2^{\text {nd }}$ report to authorities on crisis upon return from Paris

8 July - 10 November 1976: Phase 1: 17 explosions, escalating seismicity (11649 VTs recorded, 68 felt VTs), ash \& gas venting, mudflows

08 Jul $76 \quad$ EX1 8:55 1st and largest EX. Unexpected "blue sky" MF: reassuring assessment, stronger than 1956,

phreatic, no immediate danger

paroxysm, 48 min tremor, 20 min darkness, new 400

$\mathrm{m}$ fracture, cold PDC $1 \mathrm{~km}$, aquifer resurgence, lahar

$3.5 \mathrm{~km}$, ashfall. Escalating seismicity

09 Jul 76

Acid vapour jet, $\mathrm{pH}$ 1.1-3.2, strong $\mathrm{H}_{2} \mathrm{~S}$ odour to coast, $\mathrm{SO}_{2}$ ? $609 \mathrm{VT} /$ month, 12 felt $\mathrm{VT} /$ month last 3 months $(8 / 04-8 / 07)$

13 Jul $76 \quad 5$ felt VT, 14/07: 14 ppm $\mathrm{H}_{2} \mathrm{~S}$ ambiant air $3 \mathrm{~km}$ SW of

Spontaneous panic evacuation of 25,000, no official order. Traffic regulated. No implementation VCP 1st alert level.

9-10/07: Préfet evacuates hospitals (1400) and prison. 10/07: Préfet asks population to return to normal life 
Table 2 Timeline of the volcanic crisis from July 1975 - June 1977 (Continued)

\begin{tabular}{|c|c|c|}
\hline 24/25/27 Jul 76 & $\mathrm{EX} 2, \mathrm{EX} 3, \mathrm{EX} 4$ & July: Seismicity escalating $1220 \mathrm{VTS}$, \\
\hline 9 Aug 76 & EX5 & 20 felt, $81 \times$ baseline \\
\hline 12 Aug 76 & ash venting & $40 \%$ fresh vesicular glass ash \\
\hline 13 Aug 76 & ash venting & $\begin{array}{l}1194 \mathrm{VT} / \text { month, } 17 \text { felt } \mathrm{VT} / \text { month in } 3 \text { months } \\
(13 / 05-13 / 08) \text { Identification of } 40 \% \text { fresh } \\
\text { vesicular glass in ash }\end{array}$ \\
\hline
\end{tabular}

15 Aug 76

16 Aug 76

$725 \mathrm{VTs}$ in $24 \mathrm{~h}$, strongest $\mathrm{VT}$ of the crisis, $\mathrm{Md}=4.2$ (Intensity VI), felt Pointe-à-Pitre $60 \mathrm{~km}$ away

21/25 Aug $76 \quad$ EX6, EX7

24 Aug: 1527 VTs $24 \mathrm{~h}$ Strong felt VT, Md=3.9 (VI) Pointe à Pitre

\section{Aug 76}

\section{Installation of 2 tiltmeters (USGS 28/08). August:} 5989 VTs, $\geq 41$ felt, $440 x$ baseline; over last 3 months $2473 /$ month,$\geq 25$ felt VT/month (1/06 29/08)

\section{Aug 76}

New fracture splits dome SE, cold PDC 1 km, ballistics \& ashfall

$85 \%$ glass magmatic origin in $30 / 08$ explosion tephra Installation of tiltmeters by Los Alamos team (LANL)

small laterally-directed blast to $1.5 \mathrm{~km}$ SE-S, cold PDC $0.5 \mathrm{~km}$, ballistics \& ashfall, aquifer resurgence and $8 \mathrm{~km}$ lahar

Mostly $\mathrm{H}_{2} \mathrm{~S}$ in fumaroles, no or little $\mathrm{SO}_{2}$, $\mathrm{CO}_{2}$, low F

No fresh glass in ash, no deformation, tilt not usefu 12/10: report by Los Alamos shows tilt data is difficult to interpret, confirms lack of magmatic
/ $/ 07: H T+R B+8$ scientists arrive + $B R G M \cdot H T$ downplays risk; no magma, precursors to warn of paroxysm; probability of Pelean PDC extremely low, others disagree; 26/07: HT reassures Préfet and leaves for Ecuador, recommends JT to Préfet if activity increases again

10/08: JT: $\mathrm{P}$ (magma present $)=0.25 ; \mathrm{P}($ large eruption given magma present $)=0.5$

13/08: RB returns confirms MF + JT, serious escalating unrest, imminent eruption possible magma at depth

$M F$, RB, JT request urgent meeting of officials "irreversible process, directed PDC impact possible anywhere, risk area must be evacuated"

RB: magmatic gases present, expects EX of 30Mt

\section{8/08: CA + GA: arrive; 29/08: HT arrives,} downplays risk \& contradicts $\mathrm{RB}$

EX while scientists (CA, HT, GA ...) at summit, HT injured

HT reassuring, people can return to work during the day without immediate risks; RB + JT leave

15/09: Official scientific report (GA + CA): evidence precludes any optimistic interpretation of evolving unrest, major events likely in next few months/ weeks, dangerous outcome threatening

population cannot be excluded; 6/09: official Volcanic risk map (BRGM) issued to Préfet, part evacuated area (Capesterre; Vieux Habitants) now considered much less threatened; 19/09: CA arrives, reports to scientific team absence fresh glass \& to Préfet on 20/09; 21/09: CEA report shows no evidence new magmatic gas; 29/09: monitored carefully

22/07: virtually all evacuees back, normal life activities; 25/07: new spontaneous evacuation Matouba (St Claude) 29/07: financial compensation to farmers for ashfall

Matouba, Papaye, St Claude evacuated

17:30 Préfet evacuates ill, elderly, Baillif; 19:30 Préfet evacuates all S Basse-Terre except civil servants. Approx 33600 evacuated since 12/08 8:40 Préfet orders phase 2 of VCP \& evacuation of 73600 in <24h; remaining 40000 evacuated by 21:00, no injuries. Approx 2000 refused \& remain in danger zone

Préfet orders 24h evacuation of Volcano Observatory, and states a probability of 1 in 10,000 that nothing happen

3/09: Local authority CG states situation remains critical, recommends evacuation maintained for 30 days; 6/09: road blocks open 5h30-18h to allow people to return to work in all areas except BasseTerre, Gourbeyre, St-Claude where individual authorisations are required; 15/09: Préfet designates safe area for day \& night time access with new risk map (Capesterre; Vieux Habitants), school restarts in Vieux Habitants, parts of Capesterre; 28/ 09: installation of siren network where daily access permitted for authorised activities \& partial

reoccupation

1/10: Day \& night access OK as of $4 / 10$ in

5/10: HT against IPGP's erroneous report fresh glass 8/10: Given decrease unrest \& lack magmatic components in erupted ash, MF agrees opening

Capesterre, Vieux Habitants, Trois-Rivières \& Gourbeyre, with some areas assessed on individual request; access 5h-18h only in Basse-Terre, St-Claude, 
Table 2 Timeline of the volcanic crisis from July 1975 - June 1977 (Continued)

components in the ash, but the increase of sulfur in Gourbeyre, parts of Basse-Terre); 14/10: BM reports parts of Gourbeyre \& Baillif: 8/10: Préfet request to gases needs to be monitored carefully

1/6/7/10 Nov $76 \quad$ EX14, EX15, EX16, Oct: 2315 VTs, 3 felt, 154x baseline ack magma involved, stable gas chemistry and $V$ hypocentral depths; likelihood rapid onset major eruption decreased, advises continued caution. $26 /$ 10: LS favourable reopening Basse-Terre to Baillif area given new analysis and expert opinions since 5 Sept report; 27/10: Scientific Board of IPGP dismisses HT as Head of the Volcano Observatories office of IPGP. HT resigns from IPGP; LS: no evidence magma, no immediate elevated risk the Minister of the Interior that a international group of experts analyse the situation and formulate recommendations; 11/10: Préfet announces his intention to reopen as of 8 Nov schools in Trois-Rivières and Capesterre and daily activities in Basse-Terre without authorisation; 27/10: Préfe reopens Baillif, Basse-Terre and lower part of Saint-Claude for daily access without authorisation

\section{November 1976 - 4 January 1977: Phase 2: No Explosions, ash \& gas venting, lower seismicity (968 recorded VTs, 9 felt VTs), partial reoccupation of evacuated zone}

17/11: LS declares end crisis, low seismicity \& ash emissions; 15-18/11: International Scientific Committee (ISC) validates Aug evacuation, phreatic or deep magma intrusion, estimates low direct risk, recommends return of population
30 Nov 76

1-15 Dec 76
Nov: 1040 VTs, 0 felt, $69 x$ baseline; 1843 VT/ month last 3 months, 0 felt (30/08-30/11)

Strong gas jet at summit, gas temperature $184^{\circ} \mathrm{C}$ ejection blocks; Dec: $399 \mathrm{VTs}, 6$ felt, 27x baseline

\section{January - 1 March 1977: Phase 3: 9 explosions, ash \& gas venting, declining seismicity (475 recorded VTs, 7 felt VTs), total reoccupation of evacuated zone}

$\begin{array}{llll}\text { 5/13/14 Jan } & \text { EX18, EX19, EX20 } & \text { Frequent ashfalls on upper Saint-Claude, lapilli size } & \text { 29/01:Matouba \& Papaye villages closest to } \\ \text { ballistics to 1.3 km SW on 29/01; strong roaring; gas } & \text { volcano to SW isolated overnight due to ash on } \\ \text { (H/17/29 Jan } & \left.\text { EX21, EX22, EX2 } \mathrm{HO}_{2}\right) \text { odour; Jan: 312 VTs, 4 felt, 21x baseline } & \text { road, people worried }\end{array}$

13/15 Feb EX24, EX25 Ashfall on upper Saint-Claude; Feb: 179 VTs, 3 felt, 12x baseline

01-Mar $77 \quad$ EX 26: Last \& $3^{\text {rd }} \quad$ Ashfall on upper Saint-Claude, Basse-Terre, and Baillif,

largest $4 / 03$ : potable water contamination by ash. $\mathrm{SO}_{4}^{-2}>$ maximum accepted; $\mathrm{F}^{-}$almost to maximum accepted. $297 \mathrm{VT} /$ month (20x baseline) 4.3 felt VT/ month $(1 / 12-28 / 02)$

\begin{tabular}{ll}
\hline $\mathbf{2}$ March - 15 June 1977: Post-eruptive unrest phase: no explosions, no ash venting, declining seismicity (212 recorded VTs, $\mathbf{5}$ felt VTs) & Reported stinging in nose from $\mathrm{SO}_{2}$ at base of \\
28-Mar-77 & dome; March: $153 \mathrm{VTs}, 4$ felt, 10x baseline \\
& $\begin{array}{l}\text { April: } 32 \mathrm{VTs}, 0 \text { felt; May: } 19 \mathrm{VTs}, 1 \text { felt; June: } 15 \mathrm{VTs}, \\
\text { 15-Jun-77 felt, pre-crisis baseline level. Sustained degassing } \\
\text { at summit \& periphery }\end{array} \quad$ Eruption officially ends, clinics and hospitals \\
reopen
\end{tabular}

Dates in bold are pivotal dates when probabilities of eruptive outcome was queried using the BBN (Figure 5). Seismic data within each phase of the eruption is discontinuous and given only on specific key dates, the total seismicity is given in the heading of each phase. Detailed data is available in references below. EX: phreatic explosion; PDC: pyroclastic density current; RB: R. Brousse, Paris based, Expert 1 Head Government appointed Scient. Com.; HT: H. Tazieff, Paris based, Head IPGP Volc Obs, Expert 2 requested by Préfet; MF: M. Feuillard, IPGP, Head Soufrière Volc. Obs., JT: J Tomblin, Head SRU Trinidad, arrives 3/08/76 invited by Préfet (intern. expert suggested by HT on 29/07/76 given HT's departure to Ecuador); GJ: G. Jobert; Dir. IPGP from 01/08/71 till 1/08/76; CA: C. Allègre; Dir. IPGP as of 08/08/76; BRGM: Bureau de Recherches Géologiques et Minières; GA: G. Aubert Assistant Dir. INAG Nat Institute of Astronomy \& Geophysics (CNRS); RF: Richard Fiske, expert from USGS; LS: L. Steinmetz, seismologist, head of IPGP scientific team in Guadeloupe from 29/09/ 76 to 02/12/76; CG: Conseil General Guadeloupe, local government; International Scientific Commission (ISC): Chair: F. Press; members: S. Aramaki, F. Barberi, J. Coulomb, R. Fiske, P. Gasparini, C. Guillemin, G.

Sigvaldason): BM: B. Minster, hed IPGP scientific team in Gual, Préf. Gadelo 1977; De Vansay, 1979; Leno Komorowski et al. 2005 . Beauducel, 2006. 
explosive vents extended to about $1 \mathrm{~km}$ from the dome (Sheridan, 1980) before transforming into debris flows that formed from the resurgence of perched aquifers and reached up to $3.5 \mathrm{~km}$ to the east and south. The eruption was accompanied by low-temperature (100$200^{\circ} \mathrm{C}$ ) degassing of $\mathrm{H}_{2} \mathrm{O}$ and minor quantities of $\mathrm{CO}_{2}$, $\mathrm{H}_{2} \mathrm{~S}, \mathrm{SO}_{2}$, as well as acid condensates $(\mathrm{HCl}, \mathrm{HF}, \mathrm{Br})$ and a sustained renewal of fumarolic activity on and at the periphery of the dome.

Phreatic tephra consisted essentially of old hydrothermally-altered material from the dome and old pyroclastic fragments from the nearby Echelle scoria cone. Several authors (Marinelli 1976; Brousse et al. 1977; Heiken et al. 1980) reported that the phreatic products contained up to $10 \%$ by weight of fresh unaltered vitreous andesitic fragments - these were later identified as material from the underlying $1530 \mathrm{AD}$ pumice fallout deposits, although this was not understood at the time. This led to major scientific controversy as to whether there was evidence of juvenile material and therefore fresh magma in the conduit, compatible with the rapidly escalating and publicly obvious unrest. In the absence of conclusive monitoring data and independent evidence of a magmatic component, this single observation had a pivotal influence on the scientific management of the crisis, justifying a precautionary response by the authorities.

Two models have been proposed to explain the 1975-77 eruption. The more widely-accepted model interprets the crisis as a still-born magmatic event (Feuillard et al. 1983). Seismic activity from a depth of about $6 \mathrm{~km}$ is compatible with the inferred depth of a magma reservoir, and observations of $\mathrm{SO}_{2}$ provided evidence for magmatic unrest. Analysis of $\mathrm{Cl}$ levels in thermal springs sampled in the 15 years following the crisis has attributed the cause to shallow magma intrusion (Villemant et al. 2005; Boichu et al. 2011), and the chlorine isotope signature of thermal spring waters is markedly magmatic (Li et al. 2012). Feuillard et al. (1983) proposed that abnormal heat flux, either caused by magma differentiation of the 1530 AD magma batch or magma chamber replenishment, led to formation and propagation of fractures towards the surface, enabling migration of magmatic gases into the hydrothermal system. The hydrothermal system acted as a buffer, dissipating heat and magmatic gases and inhibiting magmatic eruption. Recent modelling of the flux of noble gas isotopes $\left({ }^{4} \mathrm{He} /{ }^{3} \mathrm{He}\right.$; $\mathrm{R} / \mathrm{Ra}$ ) in hydrothermal fluids suggests that either new magma is being continuously injected in the $6 \mathrm{~km}$ deep magma chamber, with a fresh batch of magma emplaced between 1959 and 1962 (Ruzié et al. 2012) or that magmatic gases are being transferred into and through the shallow magma chamber. The attendant increase of heat flux, and migration of fluids into the locally sealed hydrothermal system led to progressive pressurization and the phreatic activity of 1976-77.
A second model, proposed by Zlotnicki et al. (1992), does not invoke physicochemical changes in the magma reservoir. Rather, it proposes that aquifers become isolated (sealed) by structural readjustments or deposition of impermeable clay minerals from hydrothermal activity. This sealing is assumed to limit convective heat transfer from depth, leading to pressurization. Phreatic eruption occurs when overpressures are sufficient to cause fracturing.

The 1976-1977 eruption engendered significant and recurrent disruption and risk to the population (Le Guern et al. 1980) largely due to: 1) frequently and strongly felt volcanic seismicity; 2) atmospheric contamination by acid gases $\left(\mathrm{H}_{2} \mathrm{~S}, \mathrm{SO}_{2}\right)$ and fine corrosive volcanic dust rich in acid condensates and $\mathrm{Ca}$-sulfate that sometimes also contained non-negligible quantities of silica polymorphs; 3) contamination of potable spring waters and water tanks due to soluble acid condensates (including halogens such as fluorine, chlorine, bromine) and other trace elements adsorbed on the surface of the erupted ash; 4) chemical and mechanical consequences of the contamination of crops and grazing land due to acid condensates and trace elements adsorbed on the ash, in particular fluorine.

The 6-month evacuation of around 73,000 people (with an estimated 2000 remaining) caused severe socioeconomical difficulties for the population in southern Basse-Terre and the island as a whole, and had a profound and long-lasting influence on society. The cost of evacuation has been estimated at $60 \%$ of the total annual per capita Gross Domestic Product (GDP) of Guadeloupe in 1976 (Lepointe, 1999; Blérald, 1986) or about 342 million USD using 1976 currency rates (Kokelaar 2002); this excludes the losses of uninsured and other personal assets including open-grazing livestock and farm animals. Hence, the crisis ranks amongst one of the most costly of the 20th century (Annen and Wagner 2003), although there was no loss of life.

\section{A Bayesian Belief Network for Guadeloupe 1975-77}

A BBN has been developed to describe the fundamental processes and interactions governing volcanic activity and the state of unrest at La Soufrière from 1975 to 1976 (Figure 3). This is an extension of the model developed in Hincks (2007), following re-analysis of the literature and reports about the 1976 crisis as part of the European Union EXPLORIS project (Explosive Eruption Risk and Decision Support for EU Populations Threatened by Volcanoes, Komorowski et al. 2004) and the 2009 Agence Nationale de la Recherche funded CASAVA project (Compréhension et Analyse des Scénarios, Aléas, et risques Volcaniques aux Antilles). This BBN is a simplified conceptual model of the volcanological system depicted in Figure 2, informed by 


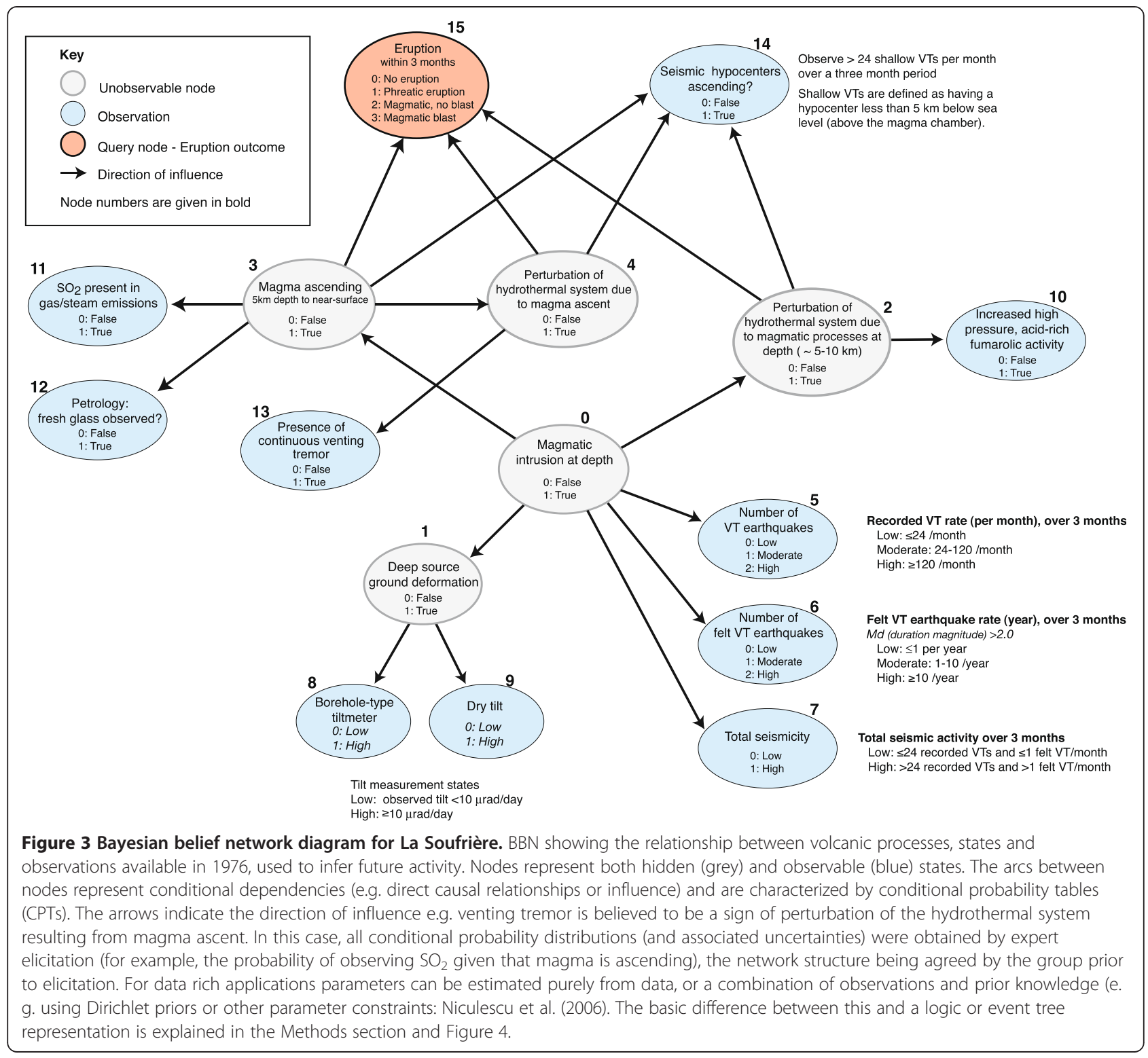

understanding of the causal relationships between processes at depth and resulting surface manifestations of activity. As the aim here is to perform a retrospective analysis of the 1976 crisis, the model is based on what was then contemporary knowledge of the volcanic system and includes only observations available at the time. The basic structure could easily be adapted to build a model for renewed activity, incorporating additional nodes and arcs to reflect the increased scope, resolution and frequency of modern monitoring, and current understanding of the various interactions and time-scales involved (e.g. rates of degassing), informed by both observation and numerical simulation.

All nodes are discrete, with mutually exclusive and exhaustive states (Figure 3). Arcs between nodes indicate direct conditional dependencies (represented by conditional probability tables - CPTs), with the arrow showing the direction of influence. Observations (nodes shown in blue) can then be used to make inferences about unobservable or 'hidden' states of the system (grey) and about the outcome of interest - whether or not an eruption will occur (the query node). This is a static network which, unlike an event tree, does not explicitly model time dependency, i.e. variables are evaluated only at a particular point in time. The probability of eruption and other unobservable states can, however, be evaluated at discrete time steps to give a changing 'hazard forecast'. Temporal associations between nodes can be incorporated in a dynamic BBN - see Future Developments.

In order to enumerate network parameters (conditional probabilities) and associated uncertainties for this analysis, we conducted a structured expert judgement 
elicitation over two days in November 2007 (see Methods, below). The group (the authors and colleagues, see acknowledgements) comprised seven volcanologists with expertise covering a range of relevant disciplines, some of whom were very familiar with the 1976 events. With the Cooke approach, a group of seven experts would be regarded as close to a minimum quorum, but here it is considered sufficient for deriving quantitative values for the BBN. Following an initial discussion of the network structure and related elicitation questions, the experts were asked to provide their personal 5, 50 and 95 percentile estimates of different volcano state probability values, taking into account uncertainties associated with the various processes, data and interpretations of evidence. After pooling these opinions into joint, group distributions (see Methods), we use the results to populate conditional probability tables (CPTs) for each node in the BBN. For example, one such question for node 1 was phrased (using the present tense) as follows: "What is the probability of ground deformation occurring due to a deep source in La Soufrière region, given magmatic intrusion has occurred at depth $(5-10 \mathrm{~km})$ ?". The elicitation questionnaire and results are provided as supplementary material to this paper [see Additional files 1 and 2]. With respect to the elicitation, a key feature of the procedure is that it encourages experts to state, independently after group discussion, their true opinion; this limits direct peer influences and other biases (Aspinall 2006, p28).

To frame the elicitation questions we chose a time scale of three months to evaluate the likelihood of observing any given phenomena or sustained level of activity. Recognizing that uncertainty in hazards forecasts increases the further ahead one looks, this time period is a pragmatic choice, appropriate in terms of decision-making in a volcanic emergency. Moreover, during the pre-eruption unrest phase at La Soufrière from June 1975 to July 1976, earthquake swarms that lasted about 1 month were separated by periods of lower seismic activity on the order of 2-3 months (Dorel and Feuillard 1980; Feuillard et al. 1983). At the Soufrière Hills Volcano, Montserrat, a time scale of six months was chosen for hazard and risk assessment during the volcanic emergency (Sparks and Aspinall 2004), this period being long enough for authorities to make and implement mitigation plans but judged short enough by the science assessment team for making useful hazards forecasts. In practice, the forecast time period can be determined by the situation and other demands, with the network nodes and structure designed to accommodate multiple time periods if necessary.

Although observations available in 1975-77 only are used in our analysis, knowledge of volcanic processes and the assessment and interpretation of monitoring data have advanced since then. The group felt it was impossible to transport themselves back fully into the state of general volcanological knowledge and mindsets of the time so the elicitation process inevitably incorporates some elements of contextual advances in the science.

\section{Methods}

\section{Bayesian Networks}

The basic concept behind the treatment of uncertainty in Bayesian Belief Networks is conditional probability (Jensen and Graven-Nielsen 2007). A BBN is a directed acyclic graph and comprises a set of variables (nodes) with either continuous or discrete state-sets, together with a set of directed links or arcs representing the direction of causality or influence between the nodes (see basic example in Figure 4a). Nodes can represent observable or hidden states of the system. A link between two nodes is described by a conditional probability distribution (CPD), with multiple state distributions entered on a Conditional Probability Table $(\mathrm{CPT})$. There are similarities with the logic or decision tree (a BBN can have a tree structure, or be approximated by a tree); however, the BBN captures conditional independence and in some cases can represent the system more compactly. The tree (Figure $4 \mathrm{~b}$ ) has a hierarchical as opposed to a network structure, and represents a sequence of events occurring in time culminating in the outcome of interest. In a $\mathrm{BBN}$, decision or logic tree, node states are mutually exclusive and exhaustive, but this is not necessarily the case in an event tree (e.g. see Marzocchi et al. 2006).

In this study, OpenPNL ${ }^{\mathrm{b}}$ (an open source $\mathrm{C}++$ library initially developed by Intel) was used for the computational BBN. A separate "link connection strength" package, an add-on to OpenPNL by Ebert-Uphoff (2007), was used to calculate mutual information (described below). There are numerous alternative software tools with graphical user interfaces which make BBN inference and analysis accessible. Many also provide API (Application Programming Interface) functionality enabling custom code to be written for automated inference and data input/output. Examples include GeNIe and SMILE (Decision Systems Laboratory 2013), Netica (Norsys 2013) and Uninet (Cooke et al. 2007).

In the static BBN presented here, data from the 1976 episode were limited and it was necessary to use expert judgement to fully describe the stochastic and scientific uncertainties. The ability of the volcanologists to quantify uncertainty was therefore critical to the reliability of the model, and we used a structured elicitation procedure (described below) to obtain collective, quantified uncertainty distributions. 
(a) An elementary BBN for magmatic unrest leading to eruption

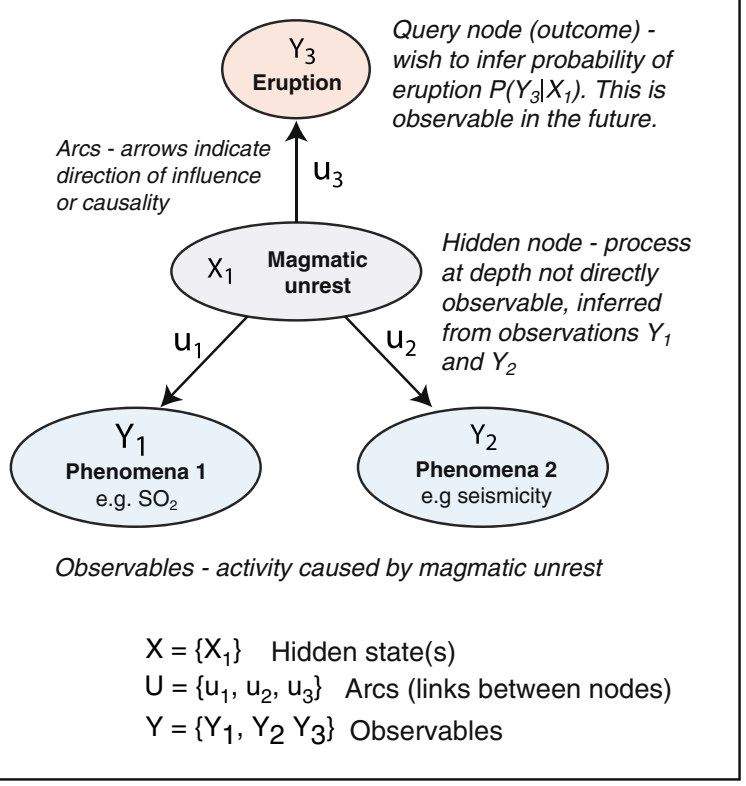

(b) Logic tree formulation of the BBN in (a)

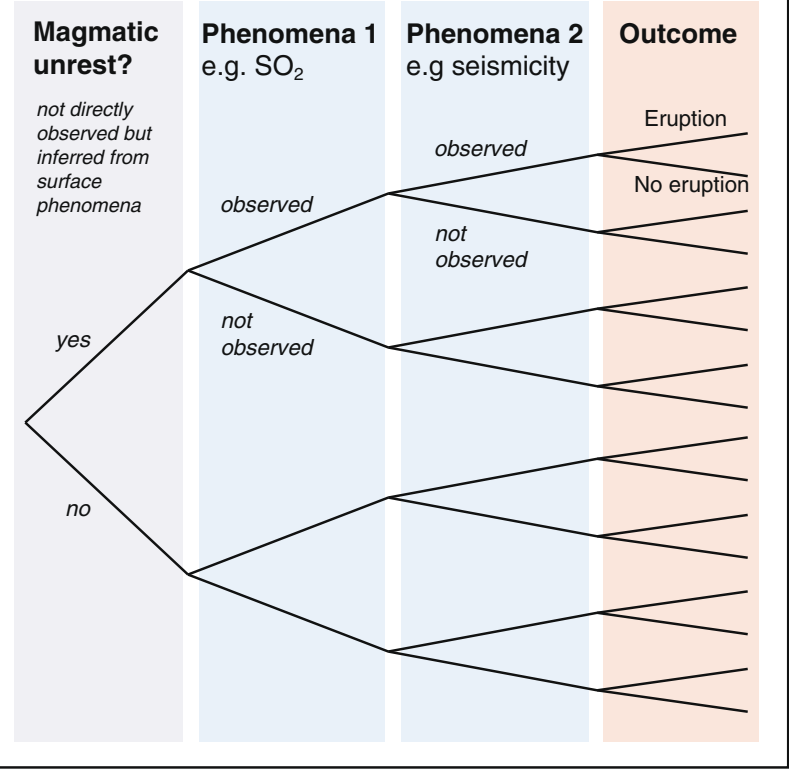

Figure 4 Comparing a Bayesian Network and logic or event tree. (a) This is an elementary BBN representing a very simple volcanological model to infer the probability of eruption resulting from magmatic unrest. Unrest (shaded grey) cannot be observed directly, and must be inferred from observations (e.g. seismicity and $\mathrm{SO}_{2}$ emission, shaded blue). The query node (shaded pink) is the outcome of interest - eruption. For a generic Bayesian Network $B=\{X, Y, U\} ; X$ represents the set of unobserved or hidden states, $Y$ the set of observable states, and $U$ the set of arcs or directed links between nodes. Arrows indicate direction of causality or influence. For the simple case where nodes are assigned discrete states, node relationships are described by conditional probability tables (CPTs). States must be mutually exclusive and exhaustive. (b) presents an equivalent logic tree representation of the basic BBN in (a). For simplicity two alternative states are shown for each node.

\section{BBN network structure}

The network structure and node states for the Guadeloupe BBN are shown in Figure 3. There are three different node types: 'hidden' or latent state nodes; 'observable' nodes, and the all-important eruption outcome 'query' node. The state of the hidden nodes (unobservable volcanic processes) and eruptive outcome can then be estimated from the input observations using Bayesian inference (see Aspinall et al. 2003). The following section describes each of the nodes in more detail. Additional file 1 documents the elicitation questions used to populate the conditional probability tables for each node in the BBN.

\section{Hidden nodes}

These represent unobservable volcanic states and processes that can only be inferred from observations.

0 Magmatic intrusion at depth. Depth is defined as $5 \mathrm{~km}$ or greater, in the region of the magma chamber. Node 0 has no parents, therefore experts were asked to estimate 5, 50 and 95 percentile values to characterize a probability distribution that new magma was being intruded in the absence of any volcanological evidence - i.e. the baseline probability of intrusion taking place at La Soufrière at any point in time (see Additional file 1 elicitation questions). This is a simple binary node the state is either true or false.

1 Deep source ground deformation. This is defined as a source at $5 \mathrm{~km}$ or greater depth, giving rise to wide field surface deformation. It is anticipated that only magmatic processes could result in such deformation. Node states: true/false.

2 Perturbation of the hydrothermal system due to magmatic processes at depth. The network considers the effects on the hydrothermal system due to magmatic processes at depth (typically 5-10 $\mathrm{km}$ ), and magma ascent (above $5 \mathrm{~km}$ depth, node 4 below) separately. Identification of either effect can be complicated by exogenic forcing (tectonic and meteorological). Node states: true/false.

3 Magma ascent. Ascent is defined as any movement of magma above the magma chamber (around $5 \mathrm{~km}$ depth) toward the near-surface. Magma need not necessarily reach the surface and could stall at shallow depth. This network node represents the probability of ascent over a three month period, given magmatic intrusion is occurring at depth. If there is no magma intrusion then the probability of 


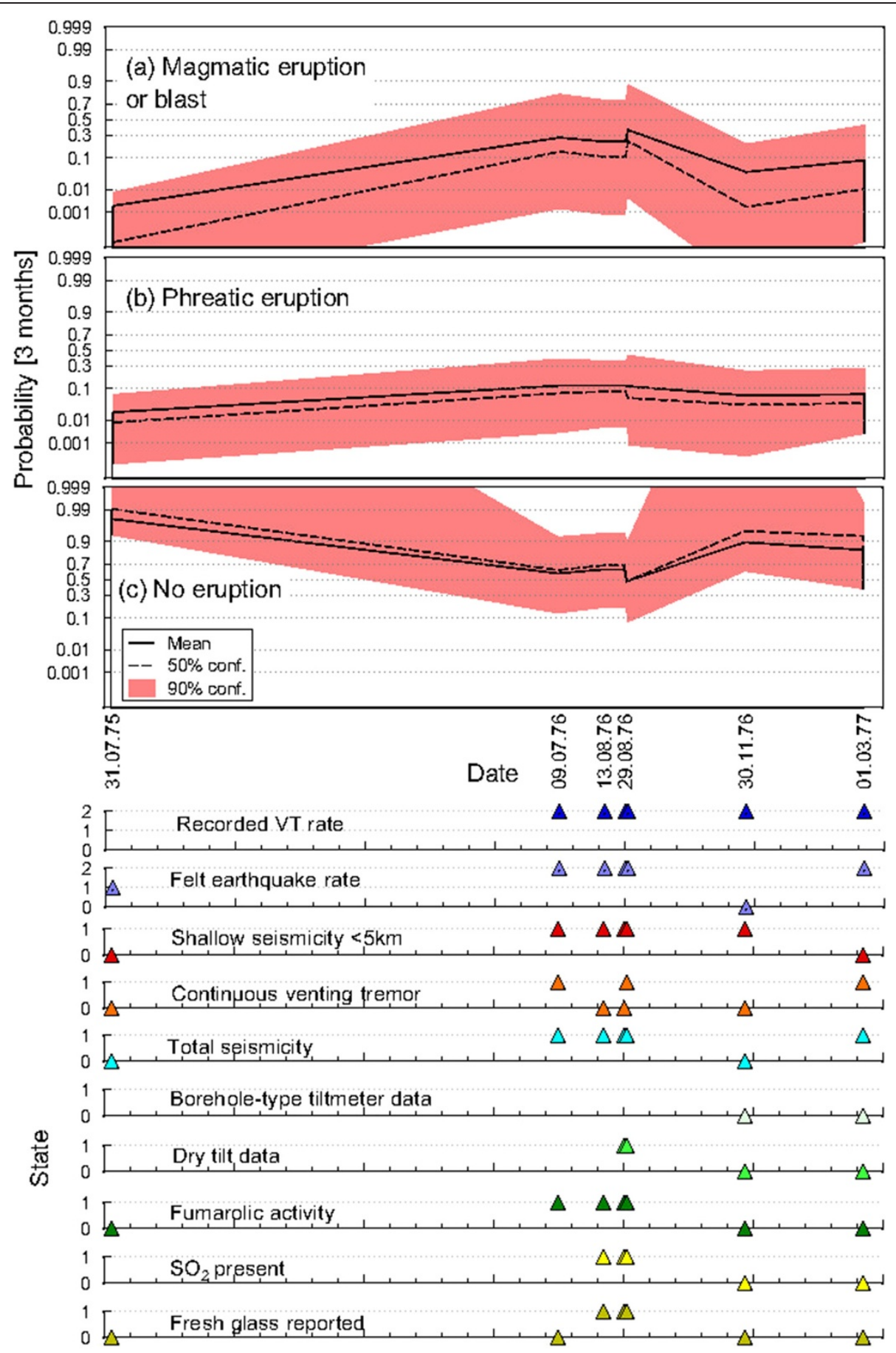

Figure 5 La Soufrière Volcano observations and eruption probabilities for July 1975 to March 1977 . Upper three panels: time variations in BBN probability estimates for: (a) a magmatic eruption or magmatic blast; (b) a phreatic eruption, or (c) no eruption, given observation states shown in the lower part of the figure. The unbroken black line denotes the expected (mean) probability estimate and the dashed line the median, as determined by Monte Carlo re-sampling of BBN input distributions; the shaded bands show the corresponding 5-95 percentile ranges, indicating the uncertainty in the forecast probability. Lower ten panels: sequence of observation states input to the BBN to estimate probability of eruption (see text).

hydrothermal perturbations due to magmatic processes at depth is assumed to be zero (and therefore not elicited). States: true/false.
4 Perturbation of the hydrothermal system due to magma ascent. As for node 2, effects can be complicated by exogenic forcing. If there is no 
magma ascent then the probability of hydrothermal perturbations due to magma ascent is zero (therefore not elicited). States: true/false.

\section{Observable nodes}

Figure 5 (lower panel) shows the time series of observational evidence input to the BBN, replicated from 1976 records and narrative accounts from Guadeloupe. As this is intended as an indicative example rather than a complete chronology of observations, these inputs span the whole crisis but focus on key dates when significant observations were made, according to contemporary reports. Computation time is very short, a few seconds, so a modern day BBN could be updated frequently and coupled with real time monitoring data streams to give near continuous hazard estimates. The following summary describes the chosen thresholds for different levels of activity for each of the observables, with some (modern) commentary on the available data, processes and reliability of evidence. The commentary reflects discussions and decisions among the expert group, referenced where possible. Volcano-tectonic earthquakes are denoted as VT.

5 Number of VT earthquakes. The baseline rate for Guadeloupe was assumed to be approximately 12 VT earthquakes per month (Dorel and Feuillard, 1980; Feuillard et al. 1983). Recent access to more detailed reports (IPGP, 1956-2013) gives a revised baseline rate of 15 recorded VTs/month and 0.2 felt $\mathrm{VTs} /$ month (as quoted in the description of eruptive unrest earlier in the manuscript); this, however, has little effect on the original findings. Three states are defined: low ( $\leq 24 /$ month, up to double the baseline rate), moderate (between 24 and 120/month) and high (greater than 120/month, or in excess of 10 times the baseline).

6 Number of felt VT earthquakes. Felt earthquakes are typically VT events with a duration magnitude (Md) of approximately 2 or greater. This node has three states: low ( $\leq 1$ felt earthquake per year), moderate (1-10/year) and high (>10/year). The baseline rate from historic records for the period from 1956 through 1975 assessed in contemporary reports (Smithsonian Institution 1976; 1977) was assumed to be approximately 0.6/year (although note that as for node 5, IPGP (1956-2013) gives a revised baseline of 0.2 felt VTs/month). There are good data on felt earthquakes associated with previous episodes of unrest (Jolivet 1958; Dorel and Feuillard 1980), and although various factors influence detection and reporting (population distribution, survival of records etc.) this noninstrumental observable is assumed to be an informative parameter, with a relatively consistent historical detection threshold. Felt VTs can also be used as a proxy for seismic energy release. However, felt VTs could be non-magmatic in origin, e.g. due to activation of faults related to disturbance of the hydrothermal system. It is possible that magmatic intrusion may occur but not be accompanied by detected or felt $\mathrm{VTs}^{\mathrm{c}}$.

7 Total seismicity. This node represents the observation of deep seismicity, and the likelihood of it being caused by magmatic intrusion. A high level of activity is defined as more than 24 recorded VT signals and more than 1 felt earthquake per month. Non-magmatic triggers could include tectonic activity associated with the regional fault system and high fluid pressures and stresses in the hydrothermal system.

8 Borehole-type tiltmeter observations. Following vigorous ash venting on the 30 August 1976, scientists from the Los Alamos National Laboratory deployed four novel borehole-type tiltmeters on the southwest flank of La Soufrière, at distances of 0.8 to $8 \mathrm{~km}$ from the vent in temporary surface installations. Measurements for the 22-23 September, 27 September and 2 October 1976 are given in West et al. (1976). In 1976 this was new, unproven, experimental technology. The instruments were not fixed in boreholes and hence the data are considered unreliable, with non-volcanic causes of tilt (e.g. ground surface instability, wind, heavy rainfall). For this node, a high tilt rate is defined as $>10 \mu \mathrm{rad} /$ day.

9 Dry tilt data. In 1976 dry tilt was considered to be an accurate and tested method, likely to detect widespread deformation. In August 1976, R. Fiske and K. Kinoshita set up four dry tilt stations on the SW flank of La Soufrière. Data for the period 29 August - 30 September are presented in Smithsonian Institution (1976) reports. The report states that tilt measurements from 1-16 October lacked coherence, likely due to effects of rainfall and evaporation at the stations. Smithsonian Institution (1977) reports "ground deformation measurements ... (pendulum, borehole, dry tilt) have indicated no significant changes in shape". We therefore assume no evidence of deformation from dry or borehole-type tilt for 30/ $11 / 76$ and $1 / 3 / 77$. High dry tilt is defined as $>10$ $\mu \mathrm{rad} /$ day.

10 Increased or decreased pressure, acid-rich fumarolic activity. Magmatic processes (degassing, interaction with groundwater etc.) can perturb the hydrothermal system and increase fumarolic activity. The presence of highly water-soluble halogen species (e.g. acids such as $\mathrm{HCl}, \mathrm{HBr}$ ) in thermal springs can be explained by magma 
intrusion and degassing that interacts with the hydrothermal system (Boichu et al. 2011 estimated a volume of $0.01-0.52 \mathrm{~km}^{3}$ of intruded magma). Halogen acids are stable in water and largely unaffected by cooling and decompression (Villemant et al. 2005). Fumarolic activity, $\mathrm{Cl}$ content of thermal springs and seismicity slowly declined in the 10-15 years following the crisis. The slow decline could be associated with reducing supply of magmatic fluids. Alternatively changes in porosity and permeability, along with self-sealing of the host rock and conduit, could reduce rates of surface degassing without the deep source flux of magmatic gases necessarily changing. The hydrothermal system could also be affected by tectonic and weather-related processes, although this was considered by the expert group to be low probability. Temperatures of fumaroles and hot springs had been measured since 1956 (Zlotnicki et al. 1992). Limited gas chromatography data existed, but problems with sampling (reaction of gas species in the sample vial during and after sampling) make these unreliable measurements (Feuillard et al. 1983). Given this uncertainty, and that regular sampling of fumaroles did not begin until after the crisis in 1979, this node has simply two states (true/ false) to capture any reported increase in fumarolic activity in the absence of reliable geochemical data. Between 1970 and 1976 the only active fumaroles were at the base of the dome, and in 1976 fumarolic activity developed rapidly on new and re-opened fractures on the summit, flanks and base of the dome. Heiken et al. (1980) report near-continuous background fumarolic activity during the period August-October 1976. Activity decreased rapidly towards the end of the crisis, ceasing first at the summit, then at the periphery in 1977, with the north fault fumarole disappearing in May 1977 (Zlotnicki et al. 1992). For purposes of this analysis we therefore assume elevated fumarolic activity was present from mid 1976, returning to a low level by 30 November 1976.

$11 \mathbf{S O}_{2}$ present in gas/steam emissions. This node represents the probability of detecting $\mathrm{SO}_{2}$, given magma ascent (or otherwise). $\mathrm{SO}_{2}$ is regarded as diagnostic of shallow depth magmatic origin (Villemant et al. 2005), however, chemical and other processes (decompression, cooling, distance from source, chemical reactions etc.) can affect concentration, speciation and the time lag from release to detection.
In assessing $\mathrm{SO}_{2}$ there is need to account for false positive and false negative observations. For example, the potential for $\mathrm{SO}_{2}$ emissions due to deep magmatic unrest, but no magma ascent above $5 \mathrm{~km}$. The meteoric system can also act as a filter or sink for chemical species that might otherwise signify magmatic activity (e.g. scrubbing of $\mathrm{SO}_{2}$ or halogen species). La Soufrière has an extensive hydrothermal system (Villemant et al. 2005; Zlotnicki et al. 2006) and scrubbing due to tropical rainfall will increase the chance of a false negative observation. Conditions at the time adversely affected the quality and frequency of observations, and as a result there are no published $\mathrm{SO}_{2}$ data from the time of the crisis (only pH). The $\mathrm{pH}$ is not diagnostic if anions $\left(\mathrm{SO}_{4}^{2-}\right.$ and $\left.\mathrm{SO}_{3}^{2}\right)$ are not analysed to rule out the contribution of acid halogens (e.g. $\mathrm{HCl}$ ) to the acidity of fumarolic condensates. Moreover false positive secondary $\mathrm{SO}_{2}$ can be formed at fumaroles due to rapid oxidation of $\mathrm{H}_{2} \mathrm{~S}$ by the atmosphere or bacteria.

\section{Petrological evidence - observation of juvenile} material. This is defined as observation of abundant, unaltered fresh juvenile glass. On 12 August 1976 some scientists identified pumice in ejecta from steam explosions, and this was presented as strong evidence for fresh juvenile material. However, this sample may have been recycled material from the previous magmatic eruption in $1530 \mathrm{AD}$ or even misidentified clay minerals. At the time juvenile glassy material was typically assumed to be vesicular, but recent research suggests otherwise. For example, non-vesicular, microlite-rich glassy fragments of the Mt St Helens cryptodome have been identified (post hoc) by Cashman and Hoblitt (2004) as a magmatic precursor. Here the experts were required to evaluate the probability of a false negative result or misclassification. Fresh glass may be present but not identified in the sample, magma may be ascending but fresh material may not be present at the surface, and old products remobilised by phreatic activity could be misidentified as fresh material.

\section{Presence of continuous venting tremor.}

Continuous tremor can be generated by gas escape or fluid flow, and episodes of tremor can be associated with phreatic explosions (e.g. Barberi et al. 1992; Young et al. 1998; Nakada et al. 1999). It is possible (although much less likely) that nonmagmatic processes such as changes in groundwater circulation or atmospheric pressure could perturb a 
hydrothermal system and generate low-level seismic tremor (e.g. Aspinall et al. 1976).

14 Seismic hypocenters ascending. This is defined as the emergence of an average of 24 or more VT earthquakes above $5 \mathrm{~km}$ depth (above the magma chamber) over three months. Such events could be caused by magma ascent (movement of magma, rock fracturing, gas escape) or alternatively hydrothermal processes driving movement of fluids, gas or steam, or fracturing. By considering a 3month period of activity significantly above the baseline, the aim is to make it easier to differentiate between ascending magmatic and static non-magmatic drivers, as it was considered unlikely that shallow seismicity would persist at such elevated and escalating levels without an element of upward-moving magmatic activity. Discussion of Hirn and Michel's (1979) post-crisis analysis of seismic hypocentres during the elicitation may have influenced the experts here - highlighting the difficulty of performing a reanalysis some 40 years on.

\section{Query node}

15 Eruption within 3 months The outcome (in any subsequent three-month period) is defined as the probability of: (a) no eruption; (b) a phreatic eruption; (c) a magmatic eruption, or (d) a magmatic blast.

\section{Expert elicitation}

A structured expert elicitation is a formalized method for assimilating group judgements in a robust and reproducible way. In a crisis, a carefully targeted elicitation can be completed in an hour or so, including expert calibration, and the findings processed within a further hour, as happened many times in Montserrat in 199596 (e.g. Aspinall et al. 2002, pp82-83).

In the present exercise, individual expert uncertainty judgements were combined with equal weights using the "Classical Model" formulation (Cooke 1991; Aspinall and Cooke, 2013) and its implementation in the EXCALIBUR software package (Cooke et al. 2000). The elicitation questions [see Additional file 1] were structured to obtain enough information to enumerate all CPTs, and hence fully characterize the BBN. To quantify uncertainty in each parameter in an elemental distribution form, the volcanologists were asked to provide lower and upper tail quantile markers, corresponding to $5 \%$ percentile and $95 \%$ percentile values, together with a median estimate to locate central tendency. Because of the small size of the group and the variety of specialisms involved, the Classical Model performance-based differential weighting option was considered not to be appropriate; instead, equal weights combinations of experts' uncertainty distributions were computed. For each variable, this took the form of a 'joint' estimate of the relevant 5, 50 and 95 percentile values, expressing the spread of uncertainty for each BBN node item; these quantiles were used to fit and parameterize standard statistical distributions ${ }^{\mathrm{d}}$ (see section below "BBN parameterization and evaluation").

\section{Elicitation responses}

The outcomes of the elicitation exercise are provided in an additional file [see Additional file 2]. Most of the responses to questions demonstrate clearly (even four decades after the event) that considerable uncertainty would still attend nearly every aspect involved in assessing the internal state of La Soufrière volcano from observations, and that the diagnostic power, in terms of eruption forecasting, is generally weak. This would have been even more so in 1976. However, this approach enables expressions of scientific uncertainty in more objective terms than possible at the time.

By and large, elicitation responses are reasonably coherent across the group, but the preponderance of wide credible intervals tends to mask any systematic differences between experts. Some of the results are informative with regard to evidential value of particular types of observations. Here we consider three specific target items (out of the 62 elicited, in total) to illustrate some generic issues.

Figure 6 shows the results of the elicitation relating to a question on the probability of observing/detecting ground deformation from a deep source in La Soufrière region. Two versions of this question, involving different conditional stipulations, were elicited: the first given there is no magmatic intrusion/unrest at depth, and the second given there is magmatic intrusion or unrest at depth. In this case, most experts judged that widespread ground deformation would accompany either intrusion or magmatic unrest. Five experts showed a high degree of confidence in the positive link, whereas the other two experts, whilst agreeing that this link was very likely, also gave a very wide uncertainty range. In contrast, all but one expert placed the likelihood of having either intrusion or magmatic unrest but no surface deformation as low. The same two experts again gave much wider uncertainties to this question than their other colleagues.

These results reflect the widespread view that surface deformation can be equated with intrusion of new magma, magma chamber replenishment or some internal magmatic event, such as convective over-turn, any one of which processes will increase pressure. The minority two experts felt that it was possible to envisage a deep magma system perturbed in some way that would not be necessarily accompanied by surface deformation. 

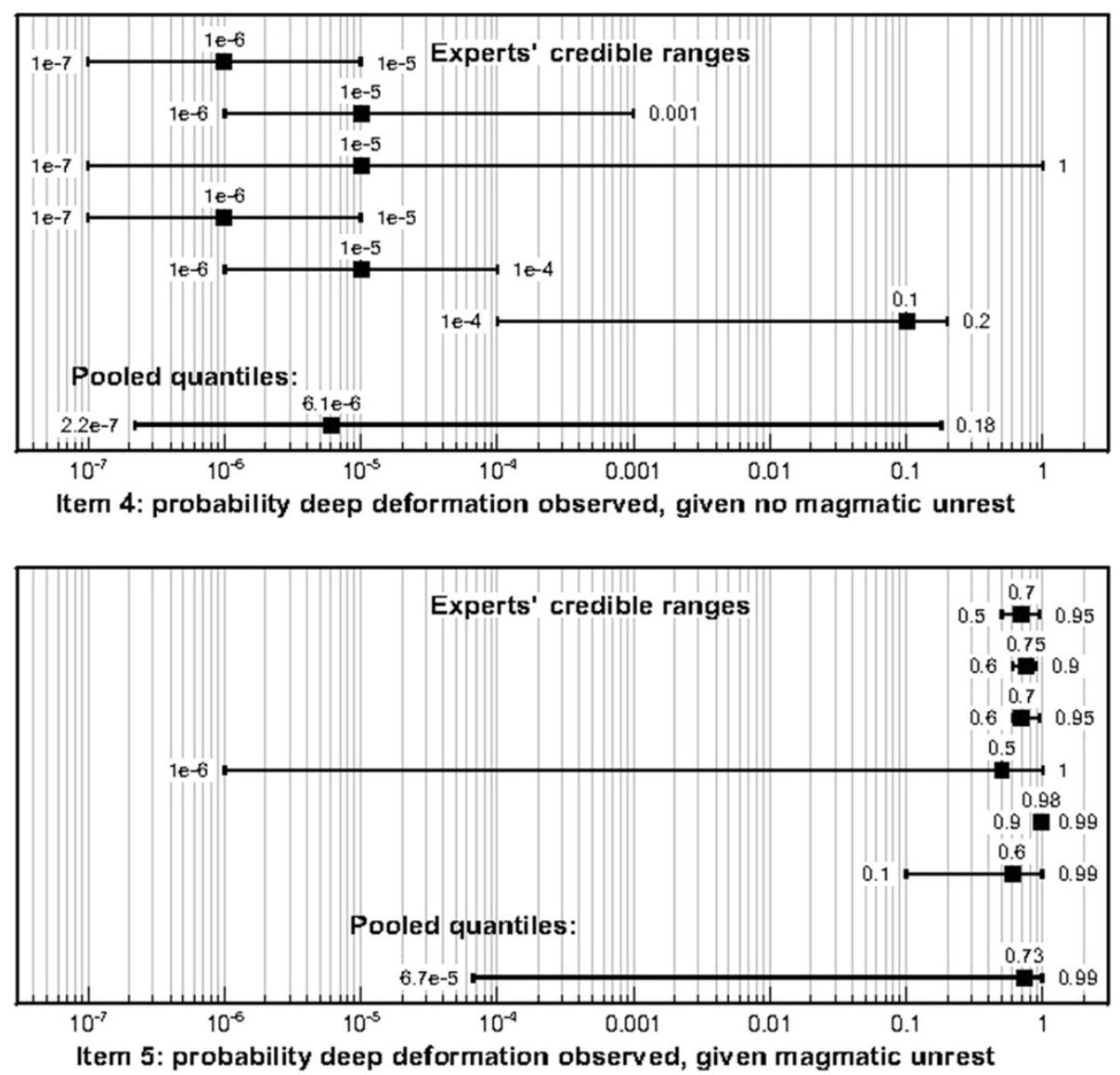

Figure 6 Example expert range graph. Plot showing the individual experts responses to a question on the probability of observing/detecting ground deformation from a deep source in La Soufrière region.

In an ideal exercise, these findings would be debated and all experts then re-elicited, having discussed the reasons why colleagues came to different conclusions. The principle here is not to enforce consensus but to be sure that all the pertinent evidence and arguments have been presented, and equally well-understood by the group.

Target Item 11 (Q12 on questionnaire [see Additional file 2]) concerns false positives for $\mathrm{SO}_{2}$ detection. Some colleagues considered that there is no diagnostic power in this information, but others suggest there is a small chance of it having evidential worth. The 1976 crisis occurred before the availability of high quality $\mathrm{SO}_{2}$ measurements from ground instruments and from satellite remote sensing. $\mathrm{SO}_{2}$ observations (now routine) would likely now be given more weight. However, experience in Montserrat indicates that $\mathrm{SO}_{2}$ data commonly remain enigmatic or ambiguous; for example, a decrease in $\mathrm{SO}_{2}$ might mean either a decline in deep activity and hence a diminution of eruption likelihood, or that gas has become trapped enhancing the prospect of an imminent explosion. As with most observables, $\mathrm{SO}_{2}$ has more evidential worth when analyzed in conjunction with changes in other observables.
With Target Item 36 (Q26 row 4 on table, Additional file 2), four experts seem convinced that there is a high probability of seeing shallow VTs when the hydrothermal system is perturbed by deep magma action but magma is not ascending, while the other three are much more cautious and gave far lower probability values. With respect to Target Items 51 and 52 (Q27 two rows on table, Additional file 2), two Experts (2 and 3) diverge from colleagues in estimating 'No eruption' or 'Phreatic eruption' probabilities when the hydrothermal system is perturbed by deep magmatic action but magma is not ascending. These are examples of "two schools of thought", where further discussion might either resolve the issue to everyone's satisfaction (i.e. some consensus is reached) or fail to resolve it so that, collectively, uncertainty is consequently high. In this case, the issue remained unresolved within the present exercise.

These examples illustrate ways in which important uncertainties in our retrospective re-appraisal of the 1975-76 crisis were brought out by adopting a structured elicitation approach. 


\section{BBN parametrization and evaluation}

For the BBN calculations, we transformed the expert group quantile marker values into a standard statistical functional distribution. Two alternative distributions were considered: Dirichlet and Generalized Trapezoidal; and results compared to find which provided the best fit to the elicited joint percentile estimates [see Additional file 3]. Best fits were determined using SolvOpt (Kuntsevich and Kappel 1997), a solver for non-smooth optimization. The solver minimizes a least-squares function: the square of the difference between the solution at each of the three percentiles and the elicited values for the percentiles. Constraints on the distribution parameters are imposed by a penalty function (e.g. setting a large but finite penalty coefficient outside the required bounds of the function). Figure 7 shows the best-fit
Dirichlet and Generalized Trapezoidal distributions for nodes 5 (recorded VT rate), 6 (Felt VT rate) and 15 (eruption) alongside the corresponding expert group quantiles. The Dirichlet distribution (i.e. the multivariate Beta) was thus chosen to characterize uncertainty distributions in the final network.

In determining the distribution parameters, some logical constraints have been applied. For example, based on past activity the probability of a magmatic blast $P$ (blast)at La Soufrière can be expected to be lower than the probability of a magmatic eruption without a blast $P$ (magmatic eruption). However, if the uncertainty spread in the estimate for $P$ (blast) is much greater than that of $P$ (magmatic eruption), and the experts gave a broader distribution, this aspect may not be captured properly by fitting a Dirichlet distribution in the standard way with

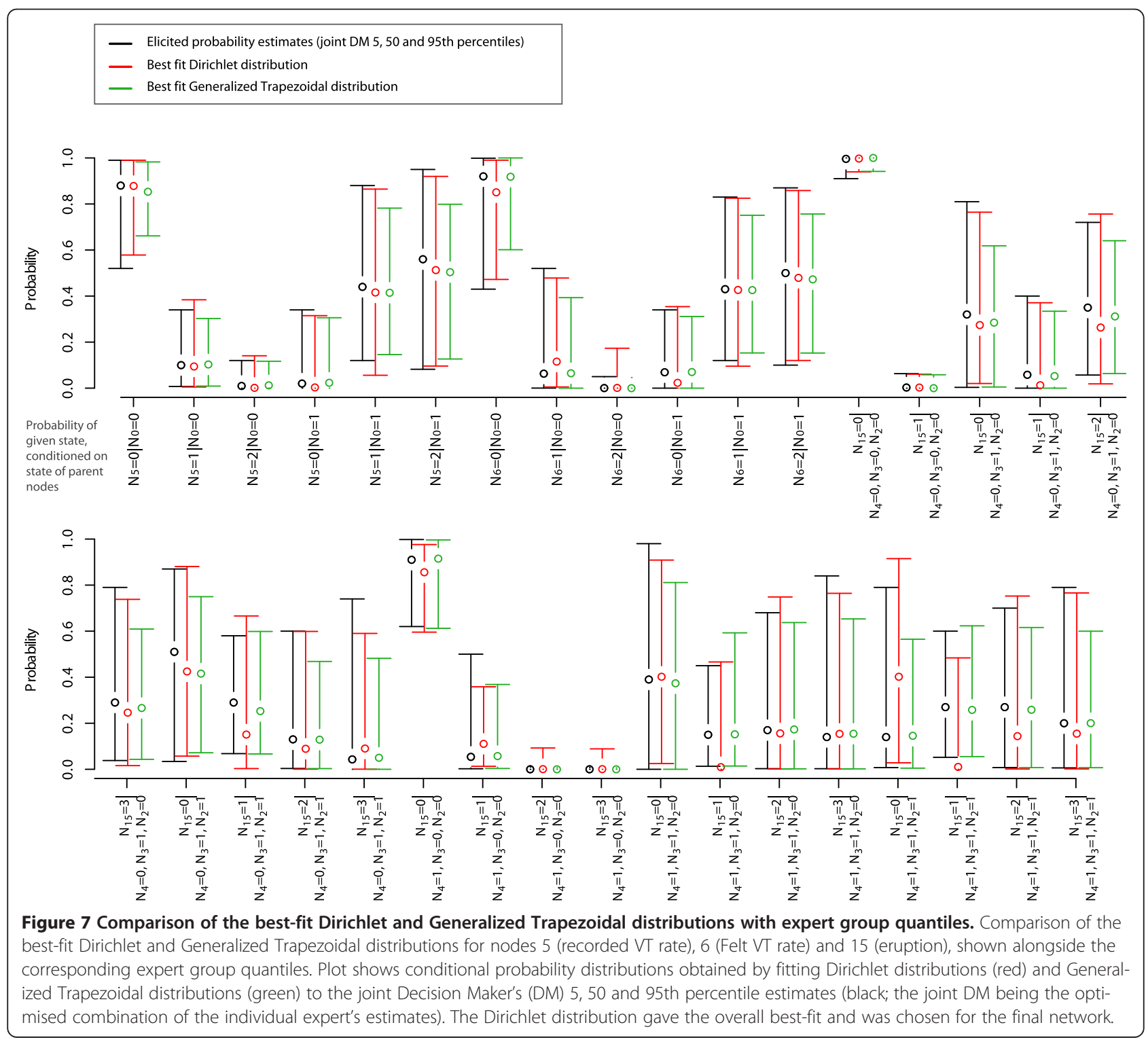


least squares (with all three percentiles weighted equally). To avoid this, we used weights of $1,1.5,1$ for the 5, 50 and $95 \%$ ile respectively - that is, giving a higher weighting to the median value, and imposed the further condition that $P($ blast $)<P$ (magmatic eruption $)$. This approach more closely reproduced the groups' 'best estimate' values, and creates a logically consistent overall outcome.

Code has been written to perform random sampling from the best-fit Beta (for binary nodes) and Dirichlet distributions for each node using the Scythe Statistical Library (Pemstein et al. 2007). Given the relevant distribution parameters, a set of random samples is returned, corresponding to the probability of each possible outcome (with the total summing to 1). These samples populate the conditional probability tables (CPTs) for each node. As there is no real basis for enforcing correlations between the elicited probability density functions, each distribution was sampled independently. Each run results in a fully-defined CPT for each node, completely parametrizing the network. At this stage we calculate various measures, such as Mutual Information and entropy (described below and in supplementary material [see Additional file 4]), which characterize the strength of node relationships and overall uncertainty. The network is updated with the time series of observational evidence (bottom panel in Figure 5), and computes the probability of each unobservable state or outcome (e.g. magmatic eruption), at each time step. The sampling procedure is repeated for a total of 10,000 runs to build output distributions for P(eruption), Mutual Information etc., the goal being to propagate uncertainty from the experts' initial estimates through to the ultimate query node.

\section{Mutual Information}

To investigate the strength of the relationship between any particular node on the BBN and the query node (eruption probability), we compute Mutual Information (MI). The MI of nodes $X$ and $Y, M I(X, Y)$, is the reduction in uncertainty (entropy) in $Y$ by knowing $X$ [see Additional file 4]. In a Bayesian Network, higher entropy means the node states are more randomly distributed, therefore more uncertain (see Bedford and Cooke 2001). Zero entropy means the state is known exactly. We can also express the strength of the relationship between nodes as Mutual Information percentage (MI\%), the percentage reduction in entropy of node $\mathrm{Y}$ given information about $\mathrm{X}$. Zero MI implies conditional independence - node X does not give any information about the state of node Y. MI (and MI\%) can be computed for any pair of nodes, regardless of whether they are directly connected. This can be used to assess how individual states and processes might affect hazard outcomes, and as a consequence, impact on risk. Computing this measure for all observables makes it possible to identify objectively which parameters provide the greatest information about future activity. As the BBN presented here has been developed using expert opinion (rather than observational data), MI is a measure of the perceived strength of connection between nodes, and the perceived value of the various observables in forecasting eruptive activity.

\section{Setting the Guadeloupe BBN in context}

The network (Figure 3) was used to infer the various hidden states (e.g. magmatic unrest or ascent) and calculate an evolving probability of eruption using the sequence of observations made between July 1975 and March 1977 (see Additional file 5 and Figure 5). Before discussing the observation-based probability estimates, we set the scheme in context by looking first at implied recurrence rates for a simple "reference scenario". In this "no signs" scenario (denoted 'no activity' in the table in Additional file 5), the assumed situation is that monitoring and observational data are continuously available, but no abnormal activity is detected in any variable. This scenario yields a median probability of magmatic blast or magmatic eruption of the order $10^{-11}$ for an eruption within a three month interval (i.e. with no unrest evident in the three months prior to eruption), with an upper $95 \%$ ile probability of order $10^{-6}$. Thus the group assessed the chance of a totally "out-of-the-blue" magmatic eruption (unaccompanied by any precursory signs) within three months to be negligible. The median probability of a phreatic eruption per three month period under the same conditions (i.e. no prior unrest) is much higher, at 0.003 (corresponding to a recurrence rate of approximately one in 80 years), while the expected (mean) probability is 0.01 (1\%, a recurrence rate of one in 25 years). Uncertainties are large, and differences between mean and median estimates signal strong skew in the distributions.

During the elicitation exercise it was not feasible to weigh up such end-member recurrence rate uncertainties in detail, not least because there is no real basis on which to calibrate them against geological and historical records. If major discrepancies were suspected, perhaps due to members of the group inflating their rate estimates to reflect their uncertainty in the absence of substantive evidence, this would invite potentially intractable debate. Faute de mieux, the rate estimates are reproduced here to illustrate how even extremely unlikely, exceptional scenarios can be accommodated in a BBN, albeit with gross uncertainties; the numbers are not definitive. 


\section{Results and discussion}

Inferring eruption probabilities using 1975-1977 observations

Figure 5 shows the sequence of estimated probabilities over the following three months for: (a) a magmatic eruption or blast, (b) phreatic eruption, or (c) no eruption, with associated uncertainties in these estimates. The solid black lines show the expected (mean) probability estimates, the broken lines indicate the medians (50th percentile), with the shaded areas outlining the 5-95 percentile ranges. The data are presented in Additional file 5.

From July 1975 until early July 1976, the likelihood of a magmatic eruption was only very marginally elevated above the assumed base-rate: at the 95\%ile level this probability would have been less than 0.01 (i.e. only a $5 \%$ chance it would be greater), while the corresponding 95\%ile probability for a phreatic explosion was 0.07 . This very limited increase in probability at the start of July 1976 indicates the influence of false positive and true negative rates for signs associated with magmatic eruption, including VT activity. If post-hoc this appears surprisingly low it serves to illustrate the challenge of setting up a CPT with appropriate diagnostic powers for the various precursors when these are poorly known $a$ priori, and can also reflect the fact that some observations can run counter to others. Perhaps even more pertinently, it illustrates potential pitfalls with hindsight interpretation of evidence: some scientists present in 1976 were quite convinced a magmatic eruption was not going to happen.

From 9 July 1976 onwards, the perceived median probability of a magmatic eruption or magmatic blast within three months increased to 0.3 , the probability of a phreatic eruption also increased (to around 0.1) [see Additional file 5] and the most likely outcome was still "no eruption". The occurrence of the explosion on 8 July 1976 did not modulate future event probabilities as these were solely conditional on observational data trends. In other words, the likelihood of another explosion in the following three months did not change in the wake of one that had just happened - incorporating this additional dependence would improve the BBN model.

The probability of a magmatic eruption fell back marginally at 13 August 1976, but rose again to peak at the end of the month when fresh glass was reported as having been detected in a microscope sample and all volcanic other phenomena were observed as present or elevated (see lower panels, Figure 5). Magmatic eruption probability remained elevated until the end of November 1976. Thereafter the states of a number of observables dropped (see Figure 5, lower panels) and the probability of eruption fell noticeably. However, it still remained above the pre-July level, and stayed there through until
March 1977 (at which time accessible data became incomplete and our analysis was curtailed). From early July 1976, the likelihood of a phreatic explosion remained elevated at a roughly constant level, reducing slightly through March 1977. Whilst uncertainty in magmatic and phreatic eruption probability was higher after 29 August 1976 than before 9 July [see Additional file 5] , lower bound estimates returned close to pre-July levels, with a corresponding shift up in the upper bound likelihood of no eruption.

The corresponding marginal distributions for probability of magmatic intrusion and ascent are given in Additional file 6 . The median probability of magmatic unrest with no precursory activity is estimated to be of the order $10^{-8}$ (mean $3 \times 10^{-4}$ ), which can be compared to the 'baseline' elicited probability of magmatic unrest (the CPT for node 0 ) - a median value of 0.08 , or 1 episode every 3.1 years. In considering this estimate, one hypothesis is that exceptionally elevated VT swarm activity is evidence of magma intrusion rather than abnormal non-magmatic hydrothermal perturbation. If we deem $\sim 15 \mathrm{VTs} /$ month to represent the baseline seismic activity related to a steadily degassing magma reservoir, observing a VT rate well above this might be taken as evidence of a switch due to upward magma intrusion from the shallow chamber. Applying this logic to the period before 1975, we find six potential instances of possible intrusion between 1956 and 1975 (including that at the beginning of the 1975-77 crisis, in July 1975). Six intrusions in 20 years implies one every 3.3 years, largely in line with the elicited joint median value of 1 event per 3.1 years. There is, however, large uncertainty in the experts' joint probability estimate - the corresponding 5 and 95 percentile estimates are $7.6 \times 10^{-5}$ ( 1 event per $\sim 3300$ years) and 0.81 (just over 3 episodes / year).

This hypothesis presumes that all phreatic eruptions are still-born failed magmatic eruptions, and that magma intruded towards the surface heated the hydrothermal system, pressurized it, opened fractures and generated VTs in competent rock, but then stalled at shallow depth. More recent occurrences of such "intrusive swarms", if that is what they are, suggest almost continuous intrusive activity from 1992, ramping up to 1997-98 when sudden and sustained chlorine degassing appeared and peaked. This is compatible with a phase of magma intrusion into the dome system, with declining degassing at its periphery but much increased gas and heat flux at the summit. An earlier, notable pulse of "intrusive swarms" occurred in 1962-1968; magma intrusion at that time is inferred by Ruzié et al. (2012), based on Noble gas isotope systematics and other data.

The question of whether all pre-1976 historical phreatic eruptions were magmatic in origin is moot. An example of an alternative hypothesis (not considered in 
our study) is that gas fluxes in magma reservoirs may be decoupled and independent of magma fluxes. Thus episodes of unrest record the transfer of gas to higher levels unaccompanied by magma. The great value of a structured probabilistic elicitation approach is that it helps raise scientific questions of this kind, and encourages development of causal conceptual models that can be tested with observations and theoretical models. The preferred conceptual model can then be used to structure a BBN, dynamically trained on the available observations (and other information) and then used to evaluate scenario probabilities for new unrest situations.

\section{BBN mutual information}

The BBN formulation allows analytic testing of node state conditionalities and uncertainty in the network. For instance, entropy is a measure of unpredictability in a system (Bedford and Cooke 2001), with higher entropy indicating the node states are more randomly distributed, and therefore more uncertain. Here we restrict our investigation to the strength of the relationship between individual nodes in the BBN and the query node, and compute corresponding Mutual Information percentages MI\% for each pair (Ebert-Uphoff 2007; see Methods and Additional file 4). MI\% is a measure of the reduction of uncertainty in the target node (eruption) due to knowledge of another node; either an observational node or an inferred latent (hidden) node. This allows us to identify which monitoring parameters provide the greatest information about future activity.

Figure 8 summarizes MI\% results: black diamonds denote the mean MI \% estimate, with boxes denoting the median (centreline) and first and third quantiles; whiskers on the plot depict 5th and 95th percentiles. In terms of eruption probability, the four most important nodes ( $0,2,3$ and $4-$ see above for definitions) are all latent factors concerning aspects of magma condition or behaviour at depth. These cannot be observed directly and can only be inferred from related observations. Deep source deformation (node 1) is a latent node with moderate potential to influence eruption probability.

In 1976, the most informative observational nodes in relation to eruption potential are inferred to be seismicity (i.e. nodes 5, 6, 13 and 14), with shallow seismicity above $5 \mathrm{~km}$ depth identified as having the strongest indicative power. In the BBN, shallow seismicity is closely associated with inferences about magma ascent, and therefore acts to influence the query node through its links to those latent nodes (e.g. nodes 3 and 4). The 1976 tilt measurements (nodes 8 and 9) and

\section{Mutual Information percentage for eruption node}

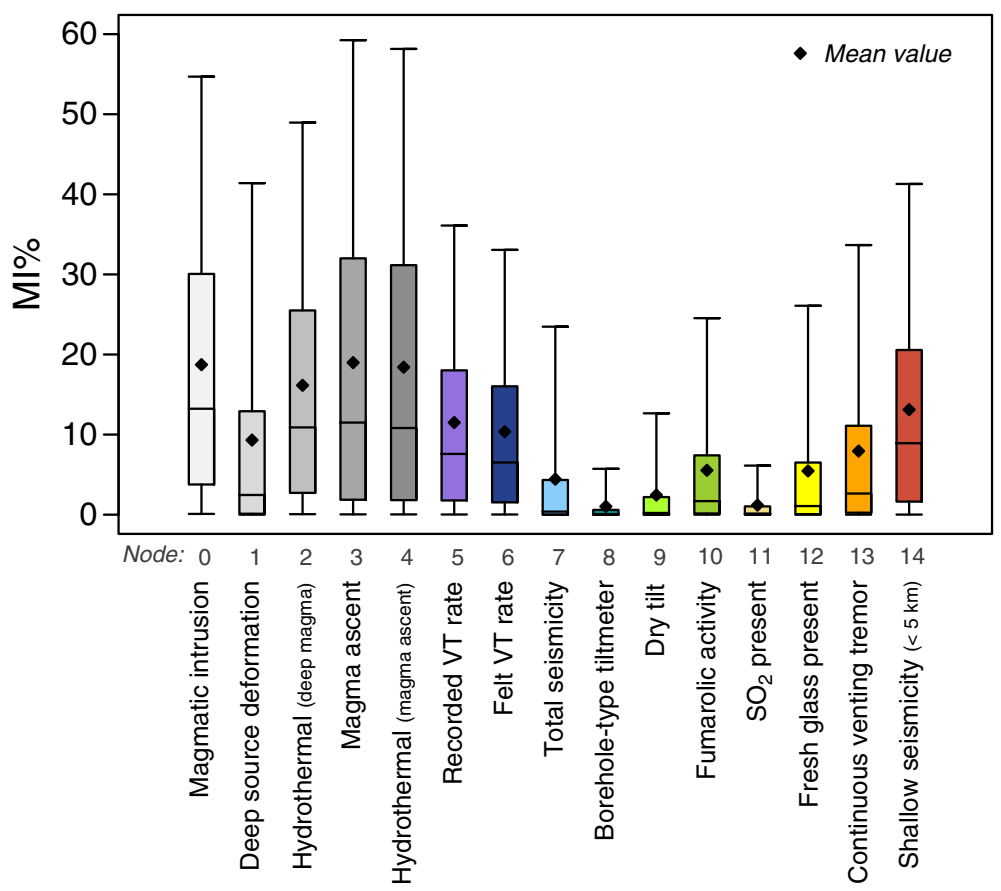

Figure 8 Mutual Information. Mutual Information (MI) is a measure of the strength of the relationship between two nodes. By computing the Ml for eruptive outcome with each observable, it is possible to identify which parameters provide the greatest information about future activity. The black diamonds denote the mean Ml \% estimate. Boxes denote the median (centreline), first and third quantiles. The whiskers on the plot denote the 5th and 95th percentiles. The data are provided in Additional file 7. 
measurements of $\mathrm{SO}_{2}$ (node 11) were of little significance for assessing eruption likelihood. These findings might be less applicable in current times with modern techniques, better instruments, and advances in data interpretation and physical models.

Identification of fresh glass (node 12) can be a valuable petrological indicator, but turned out to be a false positive here. Properly, the presence or absence of fresh glass is not a single binary yes/no parameter, and its evidential worth should be considered in conjunction with other observables. As Cashman and Hoblitt (2004) have shown, petrological evidence from early erupted products can be highly diagnostic. However, in an escalating eruption, obtaining samples can be challenging and risky, and dedicated resources are needed to perform fast petrological analysis. Rapid interpretation with a simple binocular microscope requires experience, care and awareness of context. Here the BBN formulation is indispensable - the implications should be modulated by the reliability of the observation. In the escalating sequence at Merapi 2010, for instance, evidence for vesicular material in the very earliest tephra was found in material erupted three days before the dome was first seen and then again in material before the paroxysmal dome explosion on 5 November, however the analysis was not performed until some months after the events unfolded (Komorowski et al. 2013). The example of fresh glass highlights the vital importance of characterizing fully both the diagnostic sensitivity and specificity (e.g. Sackett et al. 1996) when weighing strands of scientific evidence.

The wide uncertainty spreads shown on Figure 8 (see also Additional file 7) illustrate clearly just how weak, individually, these various indicators were for eruption forecasting on Guadeloupe in 1976. Calculation of $\mathrm{Mu}$ tual Information allows parameters that have poor diagnostic value to be identified, potentially enabling resources to be focussed on more diagnostic observations and allowing simplification of the BBN by removing links which emerge as uninformative.

\section{Discussion and conclusions}

The findings of this exploratory Bayesian Belief Network analysis of the 1976 Guadeloupe crisis lend objective support to the retrospective view that the authorities' concern for public safety and decision to evacuate were rational and defensible, given all the major scientific uncertainties that existed at the time. It is clear that even now, despite 40 years of intervening advances in research, the evidence of the time engenders considerable concern as well as uncertainty. Highly definite views, expressed at the time by some scientists, are hard to justify given the large uncertainties in the evidence, and the official precautionary decision to evacuate, given the potential consequences of an explosive magmatic eruption, is not weakened by this hindcasting analysis. The BBN analysis also helps highlight some of the challenges of providing science-based decision support under conditions of considerable uncertainty that will emerge again in a future volcanic crisis, on Guadeloupe or elsewhere.

In the present case, some of our retrospective probability estimates may be unduly or conservatively high (for example, the relatively high probability of magmatic blast as compared to other, lower intensity outcomes). In part, this may be due to the restricted scope and rather perfunctory nature of the elicitation; a more comprehensive exercise, with more experts, would be desirable. However, the BBN calculations illustrate the substantial uncertainties that are typically associated with interpreting incomplete observational information or monitoring data of limited quality. Volcanology has moved on since 1976, of course, and many monitoring techniques have improved immensely. This said, the basic evidential principles outlined here remain the same, and demonstrate how crucial it is, when resources are limited, to focus monitoring efforts on those parameters which maximise strength of inference about key hidden conditions and latent factors, such as magma ascent.

The information that goes into building the BBN model can offer considerable help in expressing and communicating scientific uncertainties and their sources, and in elucidating how forecast outcomes are sensitive to different assumptions and relationships. For example, the mutual information measure of conditional dependency between two variables is an elegant way of identifying and quantifying dependencies between elements in a system that may not be immediately obvious, especially in a complex situation involving a model with numerous inputs, nodes, and interactions.

Assessing and presenting uncertainty to policy- and decision-makers has emerged as an important topic in all branches of hazard and risk analysis, not least for the situation where we are confronted by escalating volcanic unrest (for a review of approaches to volcanic hazard assessment, see Marzocchi and Bebbington 2012). Due to the intrinsic process complexities and limitations in our understanding (present in all natural hazards domains), volcano forecasting assessments are inevitably imprecise and a sense of vagueness can be communicated through the use of confidence ranges.

Recent work by Dieckmann et al. (2010) suggests that decision makers are not necessarily 'ambiguity averse' in a forecast context, and presenting ranges of probability can have distinct advantages as a way to communicate probability and diagnostic confidence. The study by Dieckmann et al. (in a military intelligence context) 
indicated a smaller ambiguity effect in decisions that were taken when a narrative forecast was accompanied by a probability range as opposed to the same narrative with simply a point value. However, in one of their tests, it was thought that the point estimate was more useful for decision making at low probabilities. Dieckmann et al. also found that when evaluating a forecast in hindsight, their decision makers tended to report lower levels of blame and higher levels of source credibility for forecasts that reported uncertainty ranges as compared to single value point assessments. How these findings might map across to volcanic hazard forecasts and decision support situations requires further research.

\section{Future developments}

This retrospective analysis is necessarily simple in scope, reflecting the limited information available during the 1976 crisis. This said, the basic framework can easily be developed to reflect current scientific understanding and to incorporate a much wider range of monitoring data and observations. The diversification of new volcano monitoring techniques is such that a formulation for weighing and pooling multiple strands of observational evidence is becoming indispensable, especially if an audit trail is required to track science-based inputs to decisions under rapidly-changing conditions. Such a network can be utilised as an automated tool for real-time use in the volcano observatory, using streams of monitoring data to generate and continuously update probabilistic hazard forecasts.

The network presented here is a static BBN that weighs the evidence in discrete and unconnected time steps. With sufficient knowledge of the volcanic system and with comprehensive, repeated observational data, more sophisticated Dynamic Bayesian Networks (DBNs) can be constructed to model temporal relationships between nodes (Pearl 2000; Murphy 2002; Jensen and Graven-Nielsen 2007).

Whereas a static BBN describes the state of a system without using information about its prior history, a dynamic BBN can incorporate crucial information about system evolution in which the state of the volcano at any time is dependent on any number of past states. The order of such a model is the length of history, or 'memory' of the processes concerned. Dynamic BBN nodes can be tied over many time-slices to represent higher order processes, as appropriate.

One volcanological example of a DBN is the Hidden Multi-state Markov Model (HMM) of Aspinall et al. (2006). The HMM is a simple case of a DBN with a single discrete hidden node (e.g. see Rabiner 1989; Jensen 1996). The HMM model is based on the assumption that multiparameter monitoring data can be jointly evaluated to infer time to eruption, and hence used to inform hazard alert levels. For data-rich applications, network parameters and even the network structure itself can be estimated from data, using learning algorithms (Murphy 2002). Such an extension is presented in Hincks et al. (2006), which applies learning algorithms to parameterize a DBN for forecasting dome collapse on Montserrat using multiple time series of monitoring data. Determining network structure from time-evolving data is an advanced technique which would be especially salient for observational volcanology in an unrest crisis; this theme will be developed elsewhere.

\section{Endnotes}

${ }^{a}$ One of us, WPA, was present at various times in Guadeloupe in 1976, participating in monitoring activities. Another, JCK, was Director of the Guadeloupe Volcano Observatory (IPGP) from 1997 to 2001.

${ }^{\mathrm{b}}$ OpenPNL is available at http://sourceforge.net/projects/openpnl/ and https://github.com/crishoj/OpenPNL.

${ }^{\mathrm{c}}$ As, for example, in two eruptions of the nearby Soufriere of St. Vincent volcano in 1971 and 1979 (Aspinall et al. 1973; Shepherd et al. 1979). In these instances, there was almost no (recorded) precursory seismicity: in 1971 the nearest seismometer on St Vincent was $30 \mathrm{~km}$ from the volcano, while in 1979 there were seismometers on the volcano but only low-level instrumental tremor was detected and then only in the 12 hours before the first explosion.

${ }^{\mathrm{d} B o t h}$ Dirichlet and Generalised Trapezoidal distributions were compared, the Dirichlet distribution gave a better fit to the joint DM quantiles and was used in the final analysis.

\section{Additional files}

Additional file 1: Expert elicitation questionnaire. The complete set of questions addressed by the expert group during the elicitation in Bristol, 28-29 November 2007.

Additional file 2: Elicitation results. This document presents the individual experts responses to the elicitation questions, the resulting joint Decision Maker's estimates, and associated notes prepared by facilitator (W. Aspinall) immediately after elicitation responses were processed.

Additional file 3: Fitting distributions to expert group quantiles. A description of the procedure used to find the best fit distribution for the joint DM quantile marker values.

Additional file 4: Fitting distributions to expert group quantiles. A description of the procedure used to find the best fit distribution for the joint DM quantile marker values.

Additional file 5: Table showing Marginal distributions for probability of eruption, calculated for the baseline case (no activity) and given observational evidence from the period 1975-1977.

Additional file 6: Table showing Marginal distributions for probability of magmatic intrusion and ascent, calculated for the baseline case (no activity) and given observational evidence from the period 1975-1977.

Additional file 7: Mutual Information percentage (MI\%) calculated for the eruption node. Here we evaluate the perceived influence of 
each individual node in the network (both hidden and observable states) on the probability of eruption within 3 months.

\section{Abbreviations \\ BBN: Bayesian Belief Network; CPT: Conditional probability table; DBN: Dynamic Bayesian Network; DM: Decision maker (elicitation group pooling); GDSV: La Grande Découverte-Soufrière volcanic complex; HMM: Hidden Multi-state Markov Model; VT: Volcano-tectonic earthquake; VEl: Volcanic Explosivitiy Index.}

\section{Competing interests}

The authors declare that they have no competing interests.

\section{Authors' contributions}

The BBN structure was developed through discussions between the authors and all four contributed to writing the paper. R.S.J.S., W.P.A. and J-C.K. advised on the key volcanic processes and participated in the expert judgement elicitation. T.K.H. wrote the code and performed the the BBN analysis and network parameter fitting, and drafted the diagrams (with the exception of Figures 5 and 6, produced by W.P.A.). W.P.A. ran EXCALIBUR for processing elicitation responses, analysed the results of the expert elicitation; he also provided direct knowledge about monitoring and events during the 1976 Guadeloupe crisis. J-C.K. provided background information on the eruptive history, the chronology of the crisis (Tables 1 and 2), and monitoring data for La Soufrière. All authors read and approved the final manuscript.

\section{Acknowledgements}

The authors would like to thank A. Rust, J. Gottsmann and Y. Legendre for participating in the expert elicitation and their contributions to discussions. This work was supported by VOLDIES (Advanced European Research Council grant to RSJ Sparks). EU Project EXPLORIS (EVR1-2001-00047) and Aspinall \& Associates partly funded early stages of this work. Support was provided by the Institut National des Sciences de I'Univers (INSU-CNRS) and the CASAVA Project (ANR-09-RISK-02, J.C. Komorowski). JCK is grateful for valuable and insightful discussions with F. Beauducel. We gratefully acknowledge the original intellectual stimulation and advice of Dr Gordon Woo, who encouraged us to undertake this study.

\section{Author details}

'School of Earth Sciences, University of Bristol, Queen's Road, Bristol BS8 1RJ, UK. ${ }^{2}$ Institut de Physique du Globe de Paris, CNRS UMR 7154, PRES Sorbonne Paris-Cité, 1 rue Jussieu, 75238 Paris, Cedex 05, France. ${ }^{3}$ Aspinall \& Associates, Cleveland House, High Street, Tisbury SP3 6HF, UK.

\section{Received: 24 July 2013 Revised: 31 July 2013 Accepted: 3 February 2014} Published: 21 Feb 2014

\section{References}

Annen C, Wagner J-J (2003) The impact of volcanic eruptions during the 1990s. Nat Hazards Rev 4(4):169-175

Aspinall WP (2006) Structured elicitation of expert judgement for probabilistic hazard and risk assessment in volcanic eruptions. In: Mader HM, Coles SG, Connor CB, Connor LJ (ed) Statistics in Volcanology. Special Publications of IAVCEI, 1. Geological Society, London, pp 15-30

Aspinall WP, Cooke R (2013) Expert Elicitation and Judgement. In: Hill L, Rougier JC, Sparks RSJ (ed) Risk and Uncertainty assessment in natural Hazards. Cambridge University Press, Cambridge

Aspinall WP, Woo G (1994) An impartial decision-making procedure using expert judgement to assess volcanic hazards. Atti dei Convegni Lincei 112:211-220

Aspinall WP, Sigurdsson H, Shepherd JB (1973) Eruption of Soufrière volcano on St. Vincent Island, 1971-1972. Science 181:117-124

Aspinall WP, Michael MO, Tomblin JF (1976) Evidence for fluid bodies beneath the Sulphur Springs Geothermal Region, St. Lucia, West Indies. Geophys Res Lett 3:87-90

Aspinall WP, Loughlin SC, Michael FV, Miller AD, Norton GE, Rowley KC, Sparks RSJ, Young SR (2002) The Montserrat Volcano Observatory: its evolution, organisation, role and activities. In: Druitt TH, Kokelaar BP (ed) The eruption of Soufrière Hills Volcano, Montserrat, from 1995 to 1999. Geological Society, London, pp 71-92. Memoir No. 21
Aspinall WP, Woo G, Voight B, Baxter P (2003) Evidence-based volcanology: application to eruption crises. J Volcanol Geotherm Res 128(1-3):273-285

Aspinall WP, Carniel R, Jaquet O, Woo G, Hincks T (2006) Using hidden multi-state Markov models with multi-parameter volcanic data to provide empirical evidence for alert level decision-support. J Volcanol Geotherm Res 153:112-124

Barberi F, Bertagnini A, Landi P, Principe C (1992) A review on phreatic eruptions and their precursors. J Volcanol Geotherm Res 52:231-246. doi:10.1016/03770273(92)90046-G

Beauducel F (2006) À propos de la polémique de Soufrière 1976. http://www. ipgp.fr/ beaudu/soufriere/forum76.html. Accessed 21 December 2013

Bedford T, Cooke R (2001) Probabilistic Risk Analysis. Cambridge University Press, Foundations and Methods

Blérald A-P (1986) Histoire éruptive de la Guadeloupe et de la Martinique du XVIlème siècle à nos jours. Editions Karthala, Paris

Boichu M, Villemant B, Boudon G (2011) Degassing at La Soufriere de Guadeloupe volcano (Lesser Antilles) since the last eruptive crisis in 1975-77: Result of a shallow magma intrusion? J Volcanol Geotherm Res 203(3-4):102-112

Borsuk ME, Stow CA, Reckhow K (2003) Integrated approach to total maximum daily load development for Neuse River Estuary using Bayesian probability network model (Neu-BERN). J Water Res PI-ASCE 129(4):271-282

Boudon G, Semet P, Vincent PM (1987) Magma and hydrothermally driven sector collapses: the 3100 and 11500 y B.P. eruptions of La Grande Découverte (La Soufrière) Volcano, Guadeloupe, French West Indies. J Volcanol Geotherm Res 33:317-323

Boudon G, Dagain J, Semet M, Westercamp D (1988) Carte géologique à 1/ 20000e du Massif volcanique de la Soufrière, 1 sheet, Notice explicative de la carte géologique 1/20000e du Massif volcanique de la Soufrière - Carte Géologique. BRGM-CNRS-DRM-IPGP, Editions BRGM, Orléans, pp 1-43

Boudon G, Le Friant A, Komorowski J-C, Deplus C, Semet MP (2007) Volcano flank instability in the Lesser Antilles Arc: diversity of scale, processes, and temporal recurrence. J Geophys Res B 112:B08205-B08232

Boudon G, Komorowski J-C, Villemant B, Semet MP (2008) A new scenario for the last magmatic eruption of La Soufriere of Guadeloupe (Lesser Antilles) in 1530 AD Evidence from stratigraphy radiocarbon dating and magmatic evolution of erupted products. J Volcanol Geotherm Res 178(3):474-490

Brousse R, Monneyron N, Semet MP (1977) Sur la présence de verres non altérés dans les projections de la Soufrière (Guadeloupe), durant la crise de 1976. CR Acad Sci, Paris, Sér D 285:753-754

Carlut J, Quidelleur X, Courtillot V, Boudon G (2000) Paleomagnetic directions and K/Ar dating of 0 to 1 Ma lava flows from La Guadeloupe Island (French West Indias): Implications for time-averaged field models. J Geophys Res B 105(B1):835-849

Cashman KV, Hoblitt RP (2004) Magmatic precursors to the 18 May 1980 eruption of Mount St. Helens, USA. Geology 32:141-144

Cooke RM (1991) Experts in Uncertainty - Opinion and Subjective Probability in Science. Environmental Ethics and Science Policy. Oxford University Press, Series

Cooke R, Kritchallo V, Solomatine D (2000) EXCALIBUR v1.0 Delft University of Technology, The Netherlands. http://risk2.ewi.tudelft.nl/oursoftware/6excalibur. Accessed 17 July 2013

Cooke RM, Kurowicka D, Hanea AM, Morales O, Ababei DA, Ale B, Roelen A (2007) Continuous/Discrete Non Parametric Bayesian Belief Nets with UNICORN and UNINET, Proceedings of Mathematical Methods in Reliability MMR 2007. Glasgow, UK

Cowell R, Verrall R, Yoon Y (2007) Modeling Operational Risk with Bayesian Networks. J Risk Insur 74(4):795-827. doi:10.1111/j.1539-6975.2007.00235.x

De Vanssay B (1979) Les événements de 1976 en Guadeloupe: apparition d'une subculture du désastre. In: PhD thesis, Centre Universitaire Antilles-Guyane (Pointe-à-Pitre, Guadeloupe) et Ecole des Hautes Etudes en Sciences Sociales, Université Paris 5

Decision Systems Laboratory (2013) GeNle (Graphical Network Interface) software. University of Pittsburgh. http://genie.sis.pitt.edu Accessed 17 Dec 2013

Dieckmann NF, Mauro R, Slovic P (2010) The effects of presenting imprecise probabilities in intelligence forecasts. Risk Anal 30:987-1001. doi:10.1111/ j.1539-6924.2010.01384.x

Dorel J, Feuillard M (1980) Note sur la crise sismo-volcanique à la Soufriére de la Guadeloupe 1975-1977. Bull Volcanol 43(2):419-430

Ebert-Uphoff I (2007) Users Guide for the LinkConnectionStrength Package Nersion 1.0) - A PNL Package for the Calculation and Visualization of Entropy, Link Strengths and Connection Strengths in Discrete Bayesian Networks. http://www.dataonstage.com/PNL/PACKAGES/PTG_LCS/PTG_LCS. html. Accessed 5 June 2013 
Feuillard M (2011) La Soufrière de Guadeloupe: un volcan et un peuple, Jasor, Pointe-à-Pitreth edition, pp 1-246

Feuillard M, Allegre C, Brandeis G, Gaulon R, Le Mouel JL, Mercier J, Pozzi J, Semet MP (1983) The 1975-1977 crisis of La Soufrière de Guadeloupe (F.W.I): A still-born magmatic eruption. J Volcanol Geotherm Res 16:317-334

Fiske R (1984) Volcanologists, journalists, and the concerned local public: a tale of two crises in the eastern Caribbean. In: Boyd F (ed) Explosive Volcanism: Inception, Evolution and hazards. Studies in Geophysics. National Academy Press, Washington DC, pp 170-176

Heiken G, Crowe B, McGetchin T, West F, Eichelberger J, Bartram D, Peterson R, Wohletz K (1980) Phreatic eruption clouds: the activity of la Soufrière de Guadeloupe, F.W.I., August — October, 1976. Bull Volcanol 43(2):383-395. doi:10.1007/BF02598039

Hincks T (2007) Probabilistic volcanic hazard and risk assessment. University of Bristol, PhD thesis

Hincks T, Aspinall W, Woo G (2006) Evidence-based real-time hazard evaluation methodology and software for EXPLORIS volcanoes. In: Deliverable D6.4 for the project Explosive Eruption Risk and Decision Support for EU Populations Threatened by Volcanoes (EXPLORIS) EU Project EVR1-2001-00047. Available from http://exploris.pi.ingv.it/confidential/products/index.html. Accessed 17 July 2013

Hirn A, Michel B (1979) Evidence of migration of main shocks during major sismovolcanic crisis of la Soufriére (Guadeloupe, Lesser Antilles) in 1976. J Volcanol Geotherm Res 6:295-304

IPGP (1956-2013) Rapport d'activité de l'Observatoire Volcanologique et Sismologique de Guadeloupe, Catalogue de la sismicité instrumentale enregistrée en Guadeloupe, et Bilan Mensuel de l'activité Volcanique de la Soufrière et de la Sismicité régionale. In: Observatoire Volcanologique et Sismologique de la Guadeloupe, Institut de Physique du Globe de Paris, IPGP-CNRS-INSU, Conseil, Général de Guadeloupe. published online at: http:// www.ipgp.fr/pages/0303040901.php accessed 17 July 2013; unpublished database, available upon request at http://www.ipgp.fr and http:// centrededonnees.ipgp.fr/adresse.php

Jensen FV (1996) An Introduction to Bayesian Networks. Taylor and Francis, London

Jensen F, Graven-Nielsen T (2007) Bayesian Networks and Decision Graphs (Information Science and Statistics), 2nd edition. Springer, New York

Jolivet J (1958) La Crise Volcanique de 1956 à La Soufrière de La Guadeloupe. Ann Géophys 14(3):305-322

Kokelaar BP (2002) Setting, chronology and consequences of the eruption of Soufrière Hills Volcano, Montserrat (1995-1999). In: Druitt TH, Kokelaar BP (ed) The eruption of Soufrière Hills Volcano, Montserrat, from 1995 to 1999. Mem Geol Soc Lond, 21st edition, pp 1-44

Komorowski J-C, Boudon G, Semet M, Samper A, Quidelleur X, Coudret E, Le Friant A, Venat J, Paterne M, Villemant B, Beauducel F, Hammouya G (2004) Report on the eruptive history of Soufrière of Guadeloupe volcano in the last 100,000 years based on field, analytical, and bibliographic studies. In: Deliverable D2.5 for the project Explosive Eruption Risk and Decision Support for EU Populations Threatened by Volcanoes (EXPLORIS) EU Project EVR12001-00047. http://exploris.pi.ingv.it/confidential/products/Report/ DELIVERABLES/deliverable_annuale_2003.htm. Accessed 17 July 2013

Komorowski J-C, Boudon G, Semet MP, Beauducel F, Anténor-Habazac C, Bazin S, Hammouya G (2005) Guadeloupe. In: Lindsay JM, Robertson REA, Shepherd JB, Ali S (ed) Volcanic Hazard Atlas of the Lesser Antilles. Seismic Research Unit of the University of the West Indies, pp 68-107

Komorowski J-C, Legendre Y, Caron B, Boudon G (2008a) Reconstruction and analysis of sub-Plinian tephra dispersal during the 1530 A.D. Soufrière (Guadeloupe) eruption: implications for scenario definition and hazards assessment. J Volcanol Geotherm Res 178:491-515

Komorowski J-C, Boudon G, Le Friant A, Legendre Y (2008b) A remarkable Holocene record of flank-collapses at La Soufrière volcano (Guadeloupe): implications for future hazards and scenarios. In: Paper presented at the International Association of Volcanology and Chemistry of the Earth's Interior (IAVCEI). General Assembly, Reijkavik, Iceland, pp 17-23. 2008

Komorowski J-C, Jenkins S, Baxter P, Picquout A, Lavigne F, Charbonnier SJ, Gertisser R, Preece K, Cholik N, Budi-Santoso A, Surono (2013) Stratigraphy and facies relationships of explosion-generated pyroclastic density current deposits from the Merapi 2010 eruption. J Volcanol Geotherm Res 261:260-294

Kuntsevich A, Kappel F (1997) Solvopt (Solver for local optimization problems). Software. http://www.uni-graz.at/imawww/kuntsevich/solvopt/. Accessed 17 July 2013
Le Guern F, Bernard A, Chevrier RM (1980) Soufrière of Guadeloupe, 1976-1977 eruption mass and energy transfer and volcanic health hazards. Bull Volcanol 43:577-594

Legendre Y (2012) Reconstruction fine de l'histoire éruptive et scénarii éruptifs à la Soufrière de Guadeloupe: vers un modèle intégré de fonctionnement du volcan. PhD thesis. IPGP, Paris

Legendre Y, Komorowski J-C, Boudon G (2010) A multidisciplinary approach for high-resolution reconstruction of the eruptive past of La Soufrière (Guadeloupe) over the last 12000 years: Implications for hazard assessment. Geophys Res Abs, vol 12. European Geophysical Union General Assembly 2010, Vienna, pp EGU2010-EGU12719. 02-07 May 2010

Lepointe E (1999) Le réveil du volcan de la Soufrière en 1976: la population guadeloupéenne à l'épreuve du danger. In: Yacou A (ed) Les catastrophes naturelles aux Antilles - D'une Soufrière à l'autre. CERC Université Antilles et de la Guyane, Karthala, Paris, pp 15-71

Li L, Jendrzejewski N, Aubaud C, Bonifacie M, Crispi O, Dessert C, Agrinier P (2012) Isotopic evidence for quick freshening of magmatic chlorine in the Lesser Antilles arc volcanoes. Abstract presented at AGU Fall Meeting, 3-5 December 2012, San Francisco, USA. 980 V53B-2831

Loubat B, Pistolesi-Lafont A (1977) La Soufrière - à qui la faute? Presses de la Cité, Paris

Marinelli G (1976) Sur la "cendre" projetée par la Soufrière (Guadeloupe) en août 1976. CR Acad Sci Paris, Sér D 283:1731-1732

Marzocchi W, Bebbington MS (2012) Probabilistic eruption forecasting at short and long time scales. Bull Volcanol 74(8):1777-1805. doi:10.1007/s00445-0120633-x

Marzocchi W, Sandri L, Gasparini P, Newhall C, Boschi E (2004) Quantifying probabilities of volcanic events: The example of volcanic hazard at Mount Vesuvius. J Geophys Res B 109, B11201. doi:10.1029/2004JB003155

Marzocchi W, Sandri L, Furlan C (2006) A quantitative model for volcanic hazard assessment. In: Mader HM, Coles SG, Connor CB, Connor $\mathrm{L}$ (ed) Statistics in Volcanology. Special Publications of IAVCEI, 1. Geological Society, London, pp $31-37$

Marzocchi W, Sandri L, Selva J (2008) BET EF: a probabilistic tool for long- and short-term eruption forecasting. Bull Volcanol 70(5):623-632

Molina M, Fuentetaja R, Garrote L (2005) Hydrologic Models for Emergency Decision Support Using Bayesian Networks. In: Lecture Notes in Computer Science: Symbolic and Quantitative Approaches to Reasoning with Uncertainty, vol 3571, pp 88-99. doi:10.1007/11518655_9

Murphy KP (2002) Dynamic Bayesian Networks: Representation, Inference and Learning. Ph.D. thesis. Computer Science Division, UC Berkeley

Nakada S, Shimizu H, Ohta K (1999) Overview of the 1990-1995 eruption at Unzen Volcano. J Volcanol Geotherm Res 89:1-22. doi:10.1016/50377-0273 (98)00118-8

Neil M, Fenton N, Tailor M (2005) Using Bayesian Networks to Model Expected and Unexpected Operational Losses. Risk Anal 25(4):963-972. doi:10.1111/ j.1539-6924.2005.00641.x

Newhall C, Hoblitt R (2002) Constructing event trees for volcanic crises. Bull Volcanol 64(1):3-20. doi:10.1007/s004450100173

Niculescu RS, Mitchell TM, Rao RB (2006) Bayesian network learning with parameter constraints. J Mach Learn Res 7:1357-1383

Norsys (2013) Netica (Bayesian Network development software). Norsys Software Corp. http://www.norsys.com/ Accessed 17 Dec 2013

Pearl J (2000) Causality: Models, Reasoning, and Inference. Cambridge University Press, Cambridge

Pemstein D, Quinn KM, Martin AD (2007) Scythe Statistical Library: Application Programmers' Interface. http://scythe.wustl.edu/api/. Accessed 17 July 2013

Préfecture de Guadeloupe (1977) Volcan de la Soufrière en Guadeloupe: les événements de 1976. Service d'information de la Préfecture de Guadeloupe, Janvier. 1977

Rabiner L (1989) A tutorial on Hidden Markov-Models and selected applications in speech recognition. P IEEE 77(2):257-286. doi:10.1109/5.18626

Ruzié L, Moreira M, Crispi O (2012) Noble gas isotopes in hydrothermal volcanic fluids of La Soufrière of Guadeloupe (Lesser Antilles). Chem Geol 304-305:158-165

Sackett D, Rosenberg W, Gray J, Haynes R, Richardson W (1996) Evidence based medicine: What it is and what it isn't - It's about integrating individual clinical expertise and the best external evidence. Brit Med J 312(7023):71

Samper A, Quidelleur X, Lahitte P, Mollex D (2007) Timing of effusive volcanism and collapse events within an oceanic arc island: Basse-Terre, Guadeloupe archipelago (Lesser Antilles Arc). Earth Planet Sc Lett 258(1-2):175-191. doi:10.1016/j.epsl.2007.03.030 

history of the Grande Découverte Volcanic Complex, southern Basse-Terre (Guadeloupe, French West Indies) from new K-Ar Cassignol-Gillot ages. J Volcanol Geotherm Res 187(1-2):117-130

Shepherd JB, Aspinall WP, Rowley KC, Pereira J, Sigurdsson H, Fiske RS, Tomblin JF (1979) The eruption of Soufrière volcano, St Vincent April-June 1979. Nature 282:24-28

Sheridan MF (1980) Pyroclastic block flow from the September, 1976, eruption of La Soufrière volcano. Guadeloupe, Bull Volcanol 43:397-402

Siebert L, Simkin T (2002-2011) Volcanoes of the World: an Illustrated Catalog of Holocene Volcanoes and their Eruptions. In: Smithsonian Institution, Global Volcanism Program Digital Information Series, GVP-3. http://www.volcano.si. edu Accessed 17 July 2013

Smithsonian Institution (1976) Soufrière Guadeloupe. Scientific Event Alert Network (SEAN) Bulletin 01:12, September 1976

Smithsonian Institution (1977) Soufrière Guadeloupe. Scientific Event Alert Network (SEAN) Bulletin 02:02, February 1977

Sobradelo R, Martí J (2010) Bayesian event tree for long-term volcanic hazard assessment: Application to Teide - Pico Viejo stratovolcanoes, Tenerife, Canary Islands. J Geophys Res 115:B05206. doi:10.1029/2009JB006566

Sparks RSJ, Aspinall WP (2004) Volcanic Activity: Frontiers and Challenges in Forecasting, Prediction and Risk Assessment. In: Sparks RSJ, Hawkesworth CJ (ed) The State of the Planet: Frontiers and Challenges in Geophysics. American Geophysical Union, Washington, D. C.. doi:10.1029/150GM28

Spiegelhalter DJ, Dawid A, Lauritzen SL, Cowell R (1993) Bayesian-Analysis in Expert-Systems. Stat Sci 8(3):219-247

Stassopoulou A, Petrou M, Kittler J (1998) Application of a Bayesian network in a GIS based decision making system. Int J Geogr Inf Sci 12(1):23-46. doi:10.1080/136588198241996

Touboul M, Bourdon B, Villemant B, Boudon G, Joron J-L (2007) 238U-230Th226Ra disequilibria in andesitic lavas of the last magmatic eruption of Guadeloupe Soufrière, french Antilles: Processes and timescales of magma differentiation. Chem Geol 246(3-4):181-206

Villemant B, Hammouya G, Michel A, Semet MP, Komorowski J-C, Boudon G, Cheminee JL (2005) The memory of volcanic waters: Shallow magma degassing revealed by halogen monitoring in thermal springs of La Soufrière volcano (Guadeloupe, Lesser Antilles). Earth and Planet Sc Lett 237(3-4):710-728

West FG, Heiken GH, Homuth EF, Peterson RW, Crowe BM, Wohletz KH (1976) Tilts associated with Volcanic Activity, Guadeloupe, French West Indies. Informal report LA-7500-MS. Tech rep Los Alamos Scientific Laboratory, NM, USA

Woo G (2008) Probabilistic criteria for volcano evacuation decisions. Nat Hazards 45(1):87-97. doi:10.1007/s11069-007-9171-9

Young SR, Sparks RSJ, Aspinall WP, Lynch LL, Miller AD, Robertson REA, Shepherd JB (1998) Overview of the eruption of Soufriere Hills Volcano, Montserrat, 18 July 1995 to December 1997. Geophys Res Lett 25:3389-3392

Zlotnicki J, Boudon G, Le Moüel J-L (1992) The volcanic activity of La Soufrière of Guadeloupe (Lesser Antilles): structural and tectonic implications. J Volcanol Geotherm Res 49:91-104

Zlotnicki J, Vargemezis G, Mille A, Bruère F, Hammouya G (2006) State of the hydrothermal activity of Soufrière of Guadeloupe volcano inferred by VLF surveys. J Appl Geophys 58(4):265-279

\subsection{6/2191-5040-3-3}

Cite this article as: Hincks et al:: Retrospective analysis of uncertain eruption precursors at La Soufrière volcano, Guadeloupe, 1975-77: volcanic hazard assessment using a Bayesian Belief Network approach. Journal of Applied Volcanology 2014, 3:3

\section{Submit your manuscript to a SpringerOpen ${ }^{\circ}$ journal and benefit from:}

- Convenient online submission

- Rigorous peer review

- Immediate publication on acceptance

- Open access: articles freely available online

- High visibility within the field

- Retaining the copyright to your article

Submit your next manuscript at $\gg$ springeropen.com 